\title{
Palinomorfos Neogenos do Poço 2-CA-1-RS, Bacia de Pelotas, Brasil: Significado Bioestratigráfico e Paleoecológico
}

\author{
Neogene Palynomorphs from the 2-CA-7-RS Well, Pelotas Basin, Brazil: \\ Biostratigraphic and Paleoecological Significance
}

\author{
Wagner Guimarães da Silva' (wagner.guimaraes.silva@gmail.com), \\ Paulo Alves de Souza² (paulo.alves.souza@ufrgs.br), Javier Helenes³ (ihelenes@cicese.mx), \\ Mitsuru Arai ${ }^{4}$ (arai@petrobras.com.br) \\ 'Programa de Pós-graduação em Geociências - Instituto de Geociências - UFRGS \\ Av. Bento Gonçalves 9.500, CEP 91540-000, Porto Alegre, RS, BR \\ ${ }^{2}$ Departamento de Paleontologia e Estratigrafia - Instituto de Geociências - UFRGS, Porto Alegre, RS, BR \\ ${ }^{3}$ Departamento de Geología - División de Ciencias de la Tierra - CICESE, Ensenada, MX \\ ${ }^{4}$ BPA/PDEXP/CENPES/PETROBRAS, Rio de Janeiro, RJ, BR
}

Recebido em 31 de agosto de 2010; aceito em 11 de fevereiro de 2011

\section{RESUMO}

Dados de microfósseis calcários são conhecidos para a seção pré-quaternária da Bacia de Pelotas. Contudo, informações palinológicas são relativamente escassas, com estudos iniciados, de forma sistematizada, somente nos últimos anos. Este trabalho apresenta resultados palinológicos do poço 2-CA-1-RS, locado na porção onshore da bacia, no Rio Grande do Sul. Um total de 20 amostras foi selecionado no trecho entre 262 - $145 \mathrm{~m}$ de profundidade, das quais cinco revelaram associações de palinomorfos abundantes e diversificadas; quinze apresentaram predomínio de matéria orgânica amorfa ou fitoclastos. Espécies de esporos, grãos de pólen, cistos de dinoflagelados compreendem os palinomorfos mais comuns, incluindo ainda palinoforaminíferos, escolecodontes, acritarcos, algas Chlorococcales (Botryococcus) e esporos de fungos. A análise da distribuição quantitativa dos componentes da matéria orgânica particulada ao longo da seção permitiu a individualização de dois conjuntos palinológicos. Em termos gerais, os resultados indicam natureza marinha para intervalo estudado, com variações da base para o topo. O conjunto 1 (262 - $248 \mathrm{~m}$ ) reflete condições mais distais, em mar aberto, enquanto o conjunto 2 (190 - $160 \mathrm{~m})$ é interpretado como marinho mais proximal. Com base na amplitude estratigráfica de determinadas espécies de dinoflagelados, distintas idades entre o Mioceno e o Quaternário são indicadas.

Palavras-chave: Palinologia; Neógeno; Bacia de Pelotas; Brasil.

\section{ABSTRACT}

There is information available on calcareous microfossils found in the pre-Quaternary section of the Pelotas Basin. However, there is relatively sparse palynological data, since palynological studies only started to be systematically conducted in the last years. This paper presents palynological results regarding 20 samples collected between depths of 262-145 $\mathrm{m}$ in the 2-CA-1-RS well, which is located in the onshore portion of this basin, in the Rio Grande do Sul state. Five samples showed rich and diverse associations of palynomorphs and fifteen samples showed a predominance of amorphous organic matter or phytoclasts. Species of spores, pollen grains, dinoflagellate cysts, as well as microforaminiferal linigs, scolecodonts, acritarchs, Chlorococcales algae (Botryococcus) and fungal spores were also identified in this study. Quantitative analysis on the distribution of particulate organic matter along the section allowed the identification of two palynological assemblages. The results indicate marine paleoenvironments, varying from the bottom to the top, for the studied section. Assemblage $1(262-248 \mathrm{~m})$ is interpreted as distal marine environment in open ocean, whereas Assemblage $2(190-160 \mathrm{~m})$ is associated with proximal marine environments. The stratigraphic range of certain species of dinoflagellate cysts indicates ages ranging from the Miocene to the Quaternary.

Keywords: Palynology; Neogene; Pelotas Basin; Brazil. 


\section{INTRODUÇÃO}

Microfósseis calcários (nanofósseis, ostracodes e foraminíferos) são conhecidos em depósitos de idades do Cretáceo até o Holoceno da Bacia de Pelotas, com os quais zoneamentos bioestratigráficos foram elaborados, conforme sintetizado em Anjos-Zerfass, Souza e Chemale Jr. (2008), subsidiando também interpretações paleoambientais. Dados de microfósseis de parede orgânica (palinologia) são advindos, em sua grande maioria, de perfurações quaternárias (Bauermann, Behling, Macedo, 2009), restritas à Planície Costeira no Estado do Rio Grande do Sul. Um zoneamento palinoestratigráfico ainda é ausente para a bacia, uma vez que em Regali, Uesugui e Santos (1974a, 1974b), todas as bacias marginais brasileiras foram contempladas na elaboração das zonas baseadas em esporomorfos e dinoflagelados, exceto a Bacia de Pelotas.

Mais recentemente, esforços foram iniciados na tentativa do levantamento detalhado de dados palinológicos em diversos poços disponíveis da bacia, incluindo perfurações profundas da porção offshore (Arai, Masure, Lemos, 2006; Arai, 2007) e outras relativamente rasas da porção onshore. A análise das idades obtidas pelos microfósseis recuperados em diversos poços da porção emersa (onshore), corresponde à Planície Costeira do Estado, revela que os depósitos atravessados são de idades neogenas, entre o Mioceno e o Holoceno (Gomide, 1989). O poço 2-CA-1-RS, perfurado pela PETROBRAS S.A. na década de 1950 no município de Curral Alto, sul do Rio Grande do Sul, foi estudado em termos de seu conteúdo micropaleontológico (foraminíferos, ostracodes e nanofósseis) por Closs (1970), Sanguinetti (1974, 1980), Ornelas (1981), Carreño, Coimbra e Carmo $(1997,1999)$ e Gomide (1989), com sugestões de idades e interpretações de cunho paleoambiental. Na presente contribuição são apresentados dados palinológicos inéditos deste poço, com resultados bioestratigráficos e paleoambientais. Dessa forma, as informações paleontológicas do setor sul da bacia são integradas e aprimoradas, ampliando as informações preliminarmente publicadas por Silva (2008), Silva e Souza (2008) e Silva, Souza e Arai (2008).

\section{CONTEXTO GEOLÓGICO E PALEONTOLÓGICO}

A Bacia de Pelotas localiza-se no extremo sul da margem continental brasileira, desenvolvida sobre o Complexo Cristalino de idade pré-cambriana e sequências sedimentares e vulcânicas paleozoicas e mesozoicas da Bacia do Paraná. Sua origem está relacionada aos movimentos tectônicos, vinculados à fragmentação do Gondwana e a abertura do Atlântico Sul, a partir do final do Jurássico.
A porção brasileira da bacia corresponde a uma área de aproximadamente $210.000 \mathrm{~km}^{2}$, estendendo-se até a lâmina d'água de $2.000 \mathrm{~m}$ na plataforma continental, com cerca de $40.000 \mathrm{~km}^{2}$ emersos, entre os paralelos $28^{\circ}$ e $34^{\circ} \mathrm{Sul}$. O limite norte, com a Bacia de Santos, está posicionado no Alto de Florianópolis, enquanto ao sul se estende até o Alto de Polônio, no Uruguai, onde recebe o nome de Bacia del Este (Figura 1).

Modelos geológicos sobre o preenchimento sedimentar da bacia foram propostos por diversos autores, tais como Gonçalves, Oliveira e Motta (1979) e Fontana (1996), embasados em sismoestratigrafia e estratigrafia de sequências, permitindo a formulação de cartas estratigráficas (Dias et al., 1994; Bueno et al., 2007) (Figura 2). Segundo Bueno et al. (op. cit.), os depósitos iniciais da bacia são pertencentes à Supersequência Rifte (Cretáceo Inferior), subdividida em dois estágios: Rifte I, representado pelos basaltos da Formação Imbituba, e Rifte II, constituído pelas fácies siliciclásticas da Formação Cassino. A Supersequência Pós-rifte, posicionada no Cretáceo Inferior é equivale à suíte vulcânica da Formação Curumim. A Supersequência Drifte engloba três fases: a fase inicial é representada por depósitos albianos de plataforma rasa a intermediária (carbonatos e siliciclásticos da Formação Porto Belo e evaporitos mais localizados da Formação Ariri); a fase intermediária é representada por depósitos transgressivos que se estendem do Albiano ao Oligoceno, compreendendo os termos pelíticos da Formação Atlântida, que gradam para margas e siltitos, interdigitando-se com os arenitos da Formação Tramandaí; a fase final é representada por uma cunha clástica regressiva do Neógeno, compreendendo fácies das formações Cidreira e Imbé.

Ao longo do processo de abertura do Oceano Atlântico Sul, foram depositados mais de dez mil metros de sedimentos continentais, transicionais e marinhos na bacia. Parte desta sequência sedimentar está exposta na Planície Costeira do Rio Grande do Sul (PCRS) em uma ampla área de terras baixas $\left(33.000 \mathrm{~km}^{2}\right)$, ocupadas por um grande sistema de lagoas e lagunas costeiras (Villwock e Tomazelli, 1995; Tomazelli e Villwock, 2000).

A maioria das informações paleontológicas da bacia é advinda do estudo de microfósseis das seções quaternárias PCRS, sobretudo foraminíferos (Closs, 1970), palinomorfos (vide síntese em Bauermann, Behling, Macedo, 2009), diatomáceas (Hermany, 2009), com abordagem taxonômica e de reconstituição paleoambiental e paleoclimática. Megafósseis de animais também são conhecidos (Sekiguchi, 2002). Para o intervalo pré-Quaternário, os estudos são exclusivamente baseados em microfósseis, de natureza diversa, incluindo foraminíferos, ostracodes, nanofósseis calcários, braquiópodes, cuja lista de citações é relativamente 


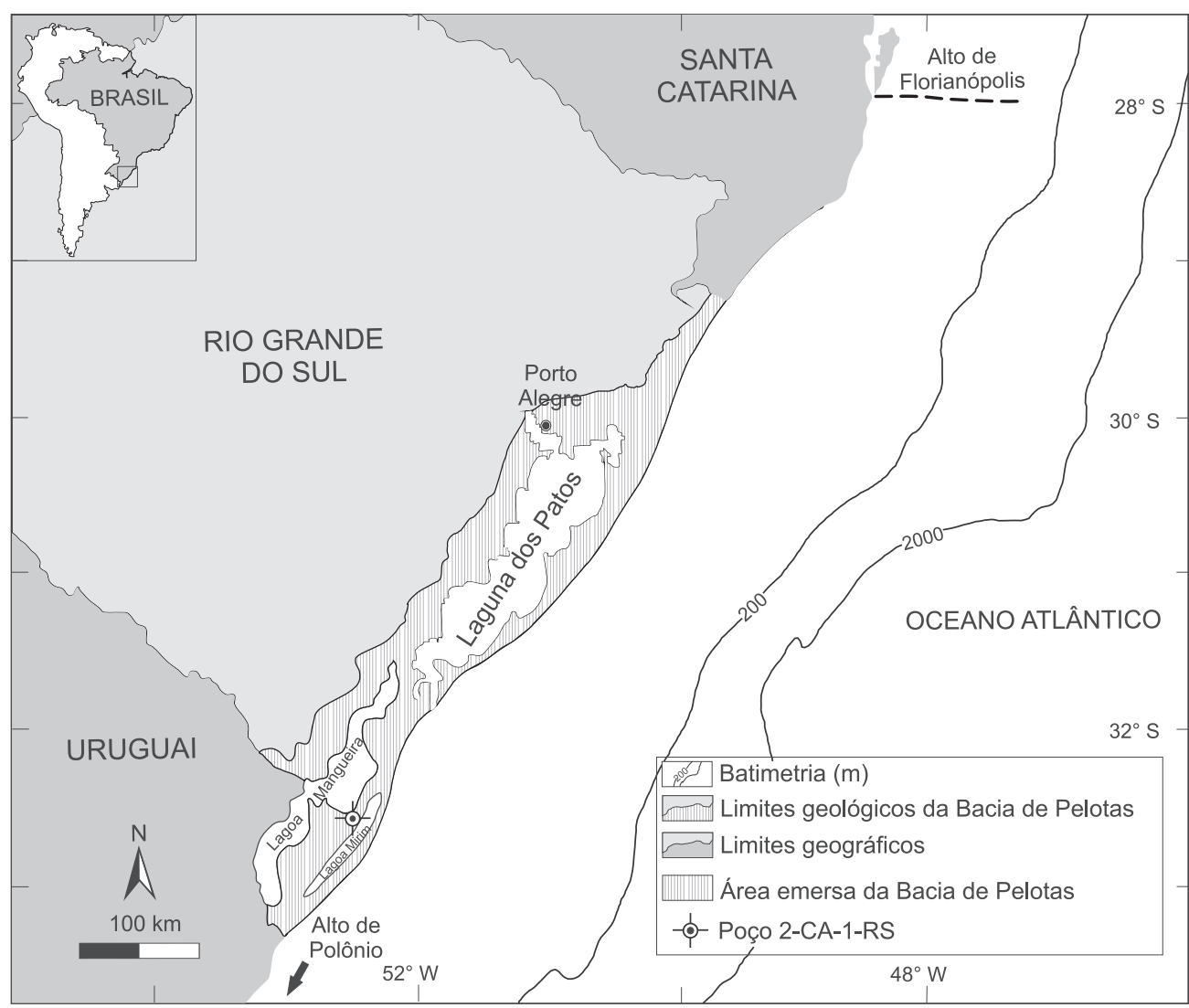

Figura 1. Localização da Bacia de Pelotas e do poço 2-CA-1-RS.

extensa, com propostas de reconstituições paleoambientais (e.g., Ornellas, 1981; Carreño, Coimbra, Carmo, 1999).

Zoneamentos bioestratigráficos com base em microfósseis foram realizados por diversos autores, conforme sintetizado em Anjos-Zerfass, Souza e Chemale Jr. (2008). Nanofósseis calcários embasam o trabalho mais significativo sobre a bioestratigrafia da bacia (Gomide, 1989), com sete zonas para o Cretáceo, duas para o Paleoceno, seis para o Eoceno, quatro para o Oligoceno, sete para o Mioceno e uma para o Pleistoceno. Nas perfurações na porção onshore da bacia, a idade mais antiga corresponde ao intervalo superior do Eomioceno, enquanto nos poços offshore ocorrem zonas correspondentes ao Albiano/Cenomaniano.

Embora haja o registro de um relatório interno realizado com base em palinomorfos (Daemon, 1969), somente nos últimos anos é que foi iniciada uma etapa de estudos palinológicos de forma sistematizada, com ênfase na identificação taxonômica dos palinomorfos e de seu uso para fins de posicionamento bioestratigráfico e reconstituição paleoambiental e paleogeográfica. A maior parte desses estudos foi publicada de forma preliminar (Arai, Masure, Lemos, 2006; Fischer et al., 2007 ; Fisher, Arai, Souza, 2008a, 2008b; Premaor et al., 2007; Premaor, Arai, Souza, 2008; Silva e Souza, 2008; Silva, Souza, Arai, 2008) ou em trabalhos monográficos inéditos (Arai, 2007; Kley, 2007; Fischer, 2008; Premaor, 2008; Silva, 2008). A análise dessas contribuições revela o potencial bioestratigráfico dos palinomorfos, especialmente de cistos dos dinoflagelados, bem como a necessidade do uso integrado dos elementos de natureza continental (esporomorfos) com as informações dos demais microfósseis de natureza marinha.

\section{MATERIAIS E MÉTODOS}

Este trabalho é baseado no estudo palinológico de 20 amostras selecionadas do poço 2-CA-1-RS (Curral Alto), localizado na PCRS, entre a Lagoa Mirim e Mangueira (Lat: $32^{\circ} 55^{\prime} 34^{\prime \prime}$ 'S Long: 52 $44^{\prime} 47^{\prime \prime} \mathrm{W}$ ) (Figura 1). As amostras são oriundas de testemunhos de sondagem, no intervalo entre $145 \mathrm{~m}$ e $262 \mathrm{~m}$ de profundidade, na maioria pelitos, alguns dos quais carbonáticos (Figura 3).

As amostras foram processadas no Laboratório de Palinologia Marleni Marques Toigo, Instituto de Geociências, Universidade Federal do Rio Grande do Sul, conforme 


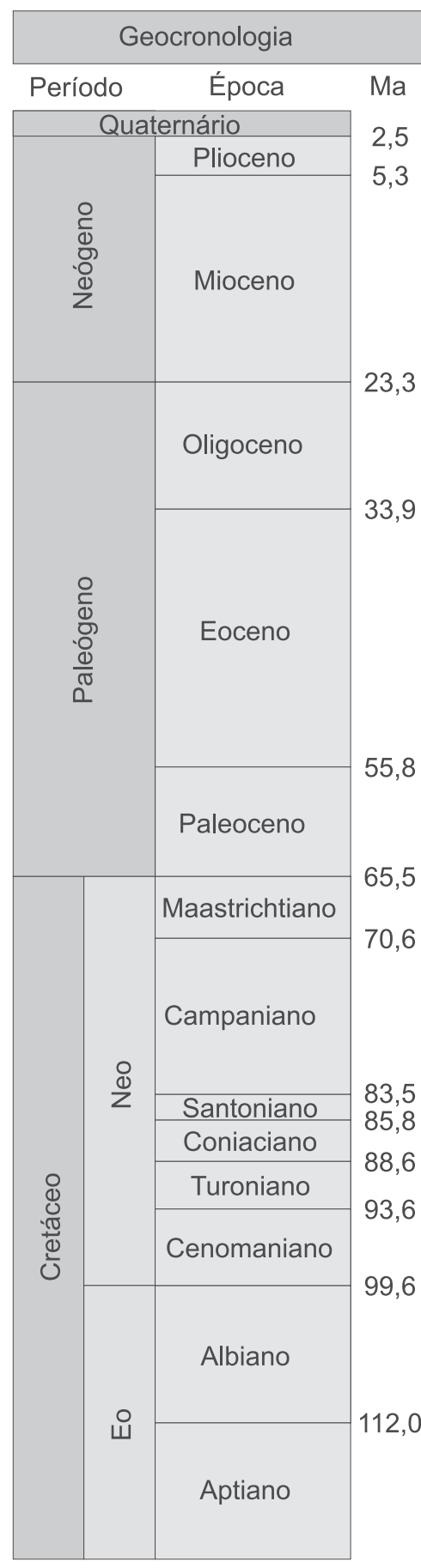

Litoestratigrafia

(Formações)

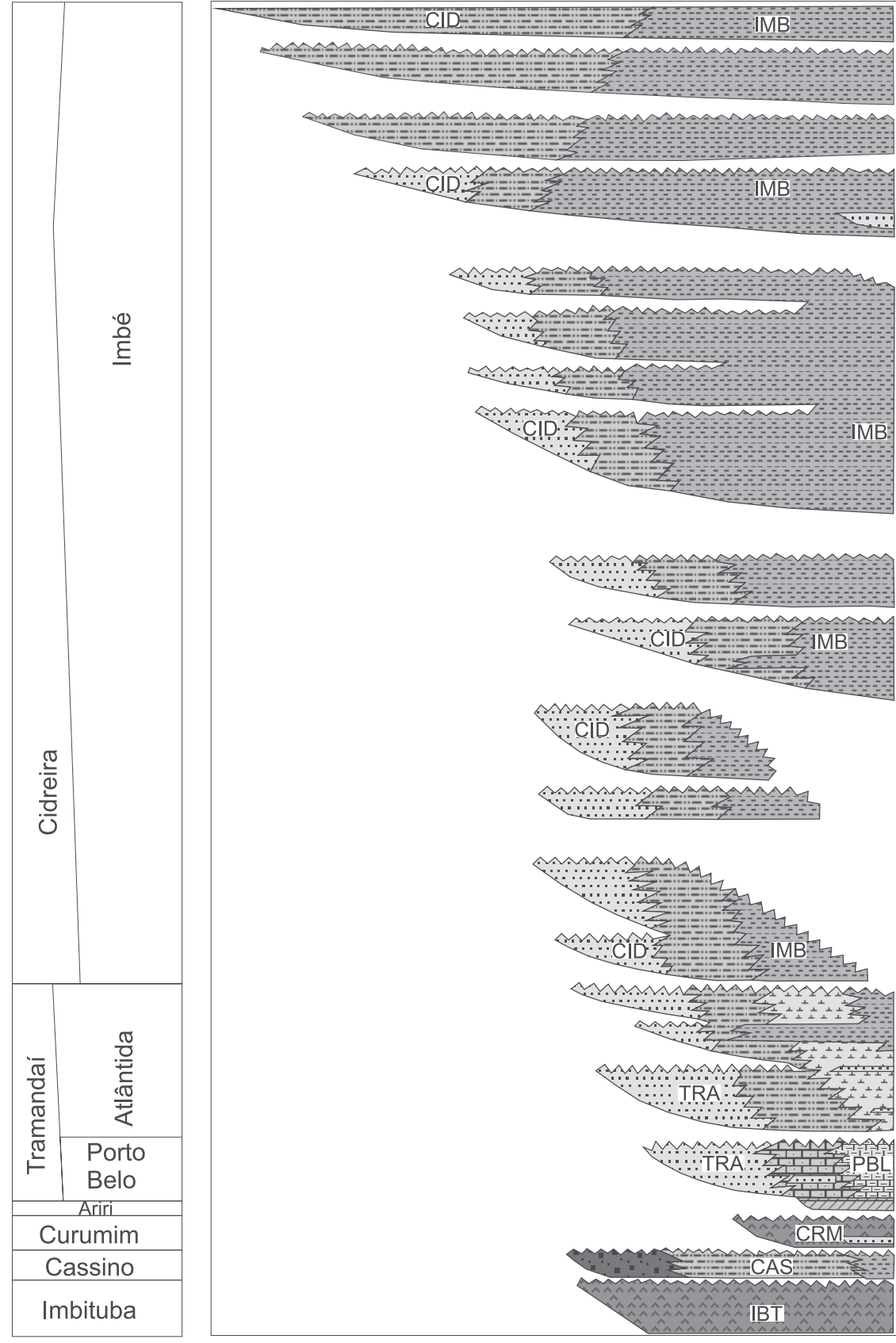

Legenda

Arenito
Evaporito

Folhelho

Figura 2. Carta cronoestratigráfica simplifica da Bacia de Pelotas (modificada de Bueno et al., 2007). 


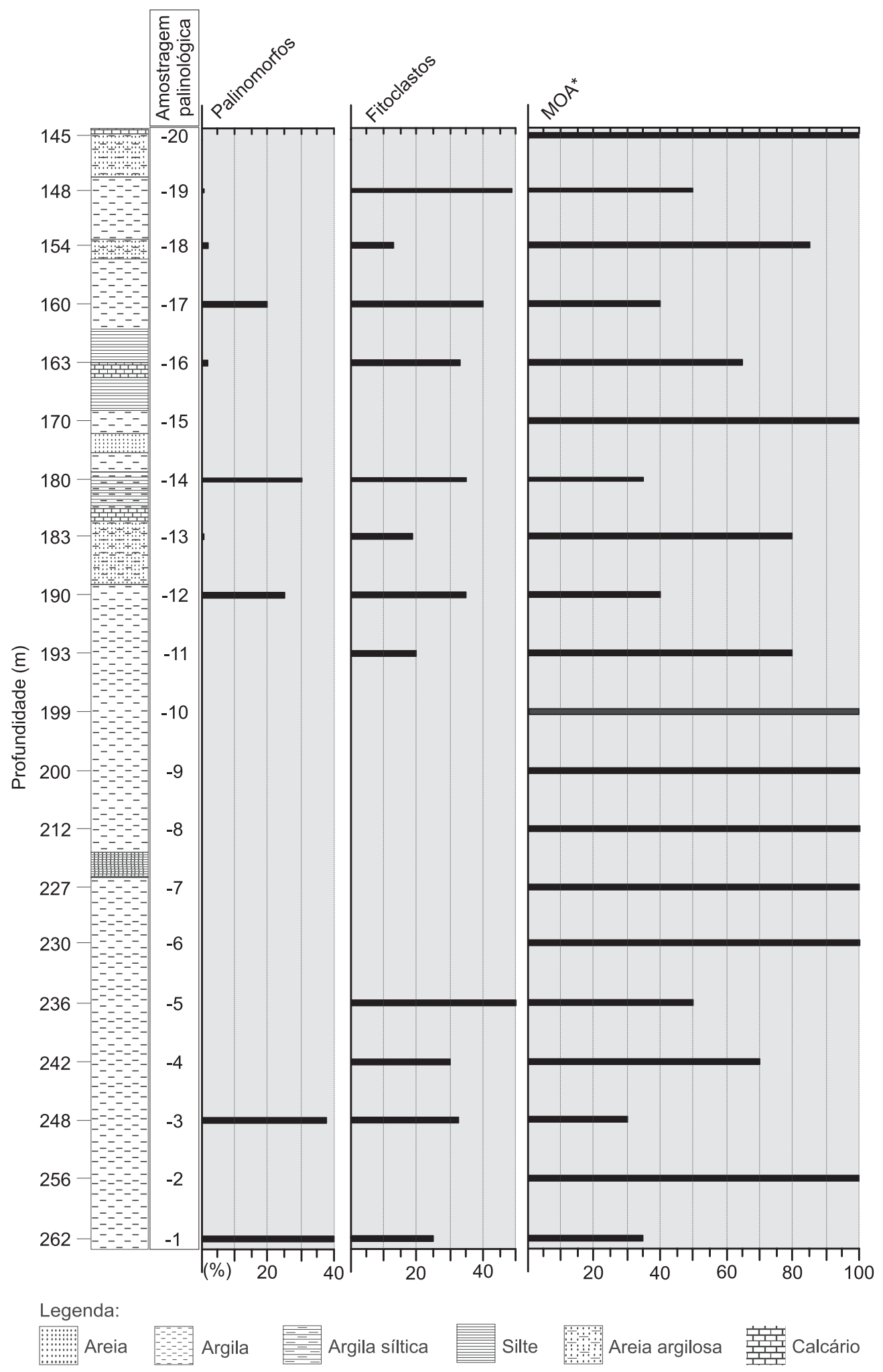

Figura 3. Perfil estratigráfico parcial do poço 2-CA-1-RS, com representação dos níveis analisados (dados litológicos de acordo com Sanguinetti, 1980) e a distribuição geral do conjunto da matéria orgânica particulada nas amostras (* matéria orgânica amorfa). 
metodologia padrão para amostras pré-quaternárias, sintetizado em Wood, Gabriel e Lawson (1996). Após a etapa de desagregação física do material, seguiu-se a adição de reagentes ácidos ( $\mathrm{HCl}$ e $\mathrm{HF}$ ) visando a dissolução da matriz mineral, permitindo a recuperação da matéria orgânica constituinte da rocha, concentrada por peneiramento entre as frações de 20 a 250 micrometros, constituindo no resíduo palinológico.

Para as análises palinológicas, o resíduo foi dividido em duas frações: a primeira mantendo o material recuperado conforme descrição anterior e a segunda com a adição de $\mathrm{KOH} 10 \%$, visando a remoção do excesso de matéria orgânica amorfa. Dessa forma, para a análise quantitativa foram utilizadas as lâminas confeccionadas a partir da primeira fração, enquanto a outra destinou-se à análise bioestratigráfica e paleoambiental, uma vez que favoreceu o reconhecimento dos palinomorfos. Adicionalmente, para identificação de espécies de parede fina e translúcida, de difícil visualização, utilizou-se corante (safranina). Um total de 65 lâminas foi confeccionado, depositadas na palinoteca do laboratório citado, sob codificação MP-P (Tabela 1).

$A$ análise da frequência da matéria orgânica particulada foi realizada a partir da contagem dos grupos constituintes dos palinomorfos (esporos, grãos de pólen, cistos de dinoflagelados, palinoforaminíferos, acritarcos, elementos algáceos, fungos, escoledocontes e palinomorfos indeterminados), fitoclastos (opacos e translúcidos) e matéria orgânica amorfa, até atingir o mínimo de 300 partículas, por nível estratigráfico. Os resultados foram tratados nos softwares Tilia e Tiliagraph (Grimm, 1987, 1990), visando a geração de gráficos de variação de composição da matéria orgânica particulada ao longo da seção estudada.

\section{RESULTADOS}

\section{Características gerais das associações}

Das vinte amostras analisadas, em cinco amostras as associações são relativamente abundantes e diversificadas, permitindo análise bioestratigráfica e paleoambiental, embora com restrições em alguns níveis; quinze apresentaram baixa recuperação de palinomorfos, com predomínio de matéria orgânica amorfa ou fitoclastos (conforme apresentado na Figura 3). Como resultado, a distribuição estratigráfica apresentada é baseada nas ocorrências dessas cinco amostras (Figuras 4, 5 e 6), considerando a escassez de palinomorfos nas demais.

Os palinomorfos recuperados no poço incluem elementos continentais: esporos, grãos de pólen, esporos de fungos; marinhos: cistos de dinoflagelados e palinoforaminíferos; além de escolecodontes. Esses microfósseis ocorrem em proporções distintas, evidenciado pelos respectivos va- lores da distribuição relativa. Doze espécies de dinoflagelados foram identificadas, sendo os gêneros Spiniferites e Selenopemphix os mais comuns. O primeiro é mais frequente nos níveis basais ( 248 e $262 \mathrm{~m}$ ) e o segundo nas amostras superiores $(160,180$ e 190 m). Dinoflagelados dos níveis basais apresentam-se fragmentados e severamente amassados, sendo melhor preservados nos níveis mais superiores. Uma característica comum aos dinoflagelados de todos os níveis é a coloração hialina, que muitas vezes os tornam imperceptíveis, ressaltados com o uso de corante.

Palinoforaminíferos ocorrem, em sua grande maioria, em ótimo estado de preservação, ocorrendo poucos espécimes fragmentados. Nos níveis basais apresentam cor acastanhada, enquanto nos níveis superiores a coloração oscila entre amarelo claro até hialino. Escolecodontes têm ótimo estado de preservação, com coloração acastanhada. Grãos de pólen e esporos apresentam estado de preservação entre regular a ótimo, com cores de castanho a hialino. Espécimes do gênero Botryococcus (Chlorococcales) apresentam bom estado de preservação e coloração amarela bem clara.

Adicionalmente, dois espécimes bem preservados de esporos retrabalhados foram registrados a $160 \mathrm{~m}$ de profundidade, atribuídos a Murospora florida (Balme) Pocock 1961 (Jurássico Inferior/Cretáceo Inferior) e Appendicisporites sp., gênero comum entre o Cretáceo e o Paleógeno.

\section{Lista de táxons identificados e distribuição estratigráfica}

Trinta e três táxons foram identificados em nível específico ou genérico com base na consulta e comparação com táxons registrados em trabalhos palinológicos do Paleógeno e Neógeno do Brasil e do exterior, tais como Regali, Uesugui e Santos (1974a, 1974b), Biffi e Grignani (1983), Lima e Dino (1984), Wrenn (1988), Lima e Angulo (1990), Lima, Melo e Coimbra (1991), Edwards e Andrle (1992), Matsuoka (1992), de Verteuil e Norris (1992). A lista completa dos táxons identificados é apresentada na Tabela 2, com a respectiva distribuição estratigráfica nos cinco níveis em que estes palinomorfos ocorrem com maior representatividade. Os táxons mais significativos estão ilustrados (Figuras 7 e 8 ) nas páginas 168 e 169 deste volume .

\section{Frequência dos grupos da matéria orgânica particulada}

As contagens realizadas objetivaram identificar a tendência de distribuição do conjunto da matéria orgânica particulada nas amostras analisadas. A contagem geral, abordando os grupos de palinomorfos (indiferenciados) $\mathrm{x}$ fitoclastos (indiferenciados) x matéria orgânica amorfa, é apresentada na Figura 3. 
Tabela 1. Lista das lâminas palinológica e suas codificações.

\begin{tabular}{|c|c|c|}
\hline $\begin{array}{l}\text { Amostragem } \\
\text { palinológica }\end{array}$ & $\begin{array}{l}\text { Profundidade } \\
\text { (m) }\end{array}$ & $\begin{array}{c}\text { Número } \\
\text { das lâminas }\end{array}$ \\
\hline 1 & 262 & MP-P $5646-5650$ \\
\hline 2 & 256,05 & MP-P $6234-6235$ \\
\hline 3 & 248 & MP-P $5635-5645$ \\
\hline 4 & 242,60 & MP-P 6233 \\
\hline 5 & 236 & MP-P 6232 \\
\hline 6 & 233 & MP-P 6231 \\
\hline 7 & 229 & MP-P 6230 \\
\hline 8 & 221 & MP-P 6229 \\
\hline 9 & 212 & MP-P 6228 \\
\hline 10 & 205 & MP-P 6227 \\
\hline 11 & 200 & MP-P 6226 \\
\hline 12 & 193,80 & MP-P 6225 \\
\hline 13 & 190 & MP-P $5622-5634$ \\
\hline 14 & 180 & MP-P $5614-5621$ \\
\hline 15 & 170 & MP-P 6224 \\
\hline 16 & 163,30 & MP-P 6223 \\
\hline 17 & 160 & MP-P $5601-5613$ \\
\hline 18 & 154,15 & MP-P 6222 \\
\hline 19 & 148,05 & MP-P 6221 \\
\hline 20 & 145 & MP-P 6220 \\
\hline
\end{tabular}

O registro de matéria orgânica amorfa (moa) é expressivo em todas as amostras, com frequências mínimas em torno de $40 \%$ nos níveis onde palinomorfos ocorrem com maior representatividade. Entre $230 \mathrm{~m}$ e $199 \mathrm{~m}$, a moa constitui o único material recuperado das lâminas, com ausência de fitoclastos e palinomorfos. De maneira geral, fitoclastos estão presentes na maioria dos níveis, com quantidades progressivamente crescentes da base para o topo. Palinomorfos são mais bem representados em cinco amostras, quais sejam: 262, 248, 190, 180 e $160 \mathrm{~m}$, cujos valores percentuais relativos são apresentados na Figura 4, com algumas características quantitativas descritas detalhadamente como seguem.

A $262 \mathrm{~m}$ de profundidade ocorre o predomínio de dinoflagelados que atingem uma frequência de $95 \%$, com palinoforaminíferos e esporos subordinados. Mesmo com redução na frequência, os dinoflagelados continuam dominantes, com uma representatividade de cerca de $70 \%$ a $248 \mathrm{~m}$, seguido por palinoforaminíferos, onde atingem seu máximo de representatividade $(20 \%)$. Neste nível, os ele- mentos continentais são representados por esporos (5\%) e grãos de pólen $(<5 \%)$, e grande participação de fitoclastos opacos.

Na amostra a 190 m há uma grande queda na representatividade dos dinoflagelados $(35 \%)$ e palinoforaminíferos ( $8 \%$ ), enquanto grãos de pólen atingem $26 \%$, seguido pelos esporos com $22 \%$, com o primeiro registro de Botryococcus (7\%). A $180 \mathrm{~m}$ os dinoflagelados alcançam $46 \%$, enquanto palinoforaminíferos atingem sua menor frequência, inferior a $5 \%$, com baixa representatividade de escolecodontes $(<5 \%)$. Palinomorfos continentais (esporos, grãos de pólen, Botryococcus) se tornam mais representativos, com $18 \%$ de esporos e $31 \%$ de grãos de pólen $31 \%$, exceto Botryococcus, que sofre queda em frequência $(<5 \%)$ em relação ao nível imediatamente abaixo.

Dinoflagelados atingem seus mais baixos níveis de frequência a $160 \mathrm{~m}$, com cerca de $8 \%$ e ausência de palinoforaminíferos. Por outro lado, palinomorfos continentais atingem seu máximo de frequência, com cerca de $90 \%$ de esporomorfos, sobretudo grãos de pólen. Botryococcus ocorre subordinadamente $(<5 \%)$.

\section{DISCUSSÃO DOS RESULTADOS}

\section{Paleoambiente}

Com base na análise da distribuição dos constituintes da matéria orgânica particulada no intervalo mais promissor (amostras entre $160 \mathrm{~m}$ e $262 \mathrm{~m}$ ), dois conjuntos palinológicos foram discriminados, denominados informalmente como conjunto 1 e conjunto 2 . O principal critério para a individualização é a relação entre os elementos marinhos e continentais, que apresentam distribuições inversamente proporcionais (Figura 4). Escolecodontes não são aqui agrupados como elementos de natureza marinha, considerando o registro desses elementos em sedimentos continentais do Paleógeno da bacias de Resende e Bonfim e folhelhos do Gráben de Casa de Pedra (Lima e Dino, 1984; Lima e Amador, 1985; Lima, Riccomini, Souza, 1994).

\section{Conjunto 1 (intervalo entre as amostras 262 a $248 \mathrm{~m}$ de profundidade)}

Esse conjunto basal é caracterizado pela grande quantidade de palinomorfos marinhos e baixa quantidade de elementos continentais e fitoclastos translúcidos, ainda que, por outro lado, fitoclastos opacos sejam relativamente bem representados. Dinoflagelados são francamente dominantes, atingindo frequências de até $95 \%$ na base do poço, com leve redução na amostra a $248 \mathrm{~m}$ (70\%). Palinoforaminíferos atingem o máximo em frequência (20\%) no poço na amostra a $248 \mathrm{~m}$. 
Tabela 2. Distribuição estratigráfica dos táxons identificados nos cinco níveis onde ocorrem com maior representatividade.

\begin{tabular}{|c|c|c|c|c|c|}
\hline \multirow[b]{2}{*}{ Palinomorfos } & \multicolumn{5}{|c|}{ Profundidade (m) } \\
\hline & 160 & 180 & 190 & 248 & 262 \\
\hline \multicolumn{6}{|l|}{ Esporos } \\
\hline Esporo indeterminado de Anthocerotaceae (Figura 8.1) & & & & - & \\
\hline Cicatricosisporites sp. 1 (Figura 8.2) & & & • & & \\
\hline Cicatricosisporites sp. 2 & & & & - & \\
\hline Cyathidites sp. & • & & & & \\
\hline Laevigatosporites ovatus Wilson e Webster 1946 (Figura 8.3) & & - & & & \\
\hline \multicolumn{6}{|l|}{ Grãos de pólen } \\
\hline Grãos de pólen indeterminados de Asteraceae & - & & & & \\
\hline Corsinipollenites undulatus (González Guzmán) Lima e Salard-Cheboldaeff 1981 (Figura 8.5) & & • & & & \\
\hline Grãos de pólen indeterminados de Poaceae (Figura 8.6) & • & & & & \\
\hline Podocarpidites (Cookson 1947 ex Couper 1953) emend. Potonié 1958 (Figura 8.4) & • & - & - & - & - \\
\hline Retistephanocolpites gracilis Regali, Uesugui e Santos 1974 (Figura 8.7) & • & & & & \\
\hline Grãos de pólen indeterminados de Rubiaceae (Figura 8.8) & • & & & & \\
\hline \multicolumn{6}{|l|}{ Dinoflagelados } \\
\hline Lejeunecysta globosa Biffi e Grignani 1983 (Figura 7.1) & & & & • & \\
\hline Lejeunecysta hyalina (Gerlach 1961) Artzner e Dörhöfer 1978 (Figura 7.2) & & & & • & \\
\hline Lejeunecysta oliva (Reid) Turon e Londeix 1988 (Figura 7.3) & - & & & & \\
\hline Lejeunecysta sabrina (Reid) Bujak 1984 (Figura 7.4) & - & & & & \\
\hline Lejeunecysta cf. beninensis Biffi e Grignani 1983 & & & & - & \\
\hline Lejeunecysta cf. globosa (Figura 7.5) & & - & & & \\
\hline Lingulodinium machaerophorum Deflandre e Cookson 1955 & & & & • & - \\
\hline Nematosphaeropsis rigida Wrenn 1988 (Figura 7.6) & & & • & • & - \\
\hline Quinquecuspi concreta (Reid 1977) Harland 1977 (Figura 7.7) & & - & & & \\
\hline Selenopemphix brevispinosa Head et al.1989 (Figura 7.8) & & & & & $\cdot$ \\
\hline Selenopemphix dionaeacysta Head et al. 1989 (Figura 7.9) & & • & & & - \\
\hline Selenopemphix nephroides Benedek 1972 & & • & & • & \\
\hline Selenopemphix quanta (Bradford 1975) Matsuoka 1985 (Figura 7.10) & • & - & • & & \\
\hline Spiniferites bulloideus Deflandre e Cookson 1955 (Figura 7.11) & & & & & - \\
\hline Spiniferites mirabilis (Rossignol 1964) Sarjeant 1970 (Figura 7.12) & • & & & & - \\
\hline Spiniferites sp. 1 & & & - & • & - \\
\hline \multicolumn{6}{|l|}{ Palinoforaminíferos } \\
\hline Palinoforaminíferos indeterminados (Figura 8.10) & & • & • & • & - \\
\hline \multicolumn{6}{|l|}{ Escolecodonte } \\
\hline Escolecodontes indeterminados (Figura 8.11) & • & • & • & - & - \\
\hline \multicolumn{6}{|l|}{ Acritarco } \\
\hline Acritarcos indeterminados & - & & & & \\
\hline \multicolumn{6}{|l|}{ Clorofíceas } \\
\hline Botryococcus spp. (Figura 8.9) & - & • & • & & \\
\hline \multicolumn{6}{|l|}{ Fungos } \\
\hline Tetraploa spp. & • & & & - & \\
\hline \multicolumn{6}{|l|}{ Esporos retrabalhados } \\
\hline Appendicisporites sp. & • & & & & \\
\hline Murospora florida (Balme) Pocock 1961 & • & & & & \\
\hline
\end{tabular}




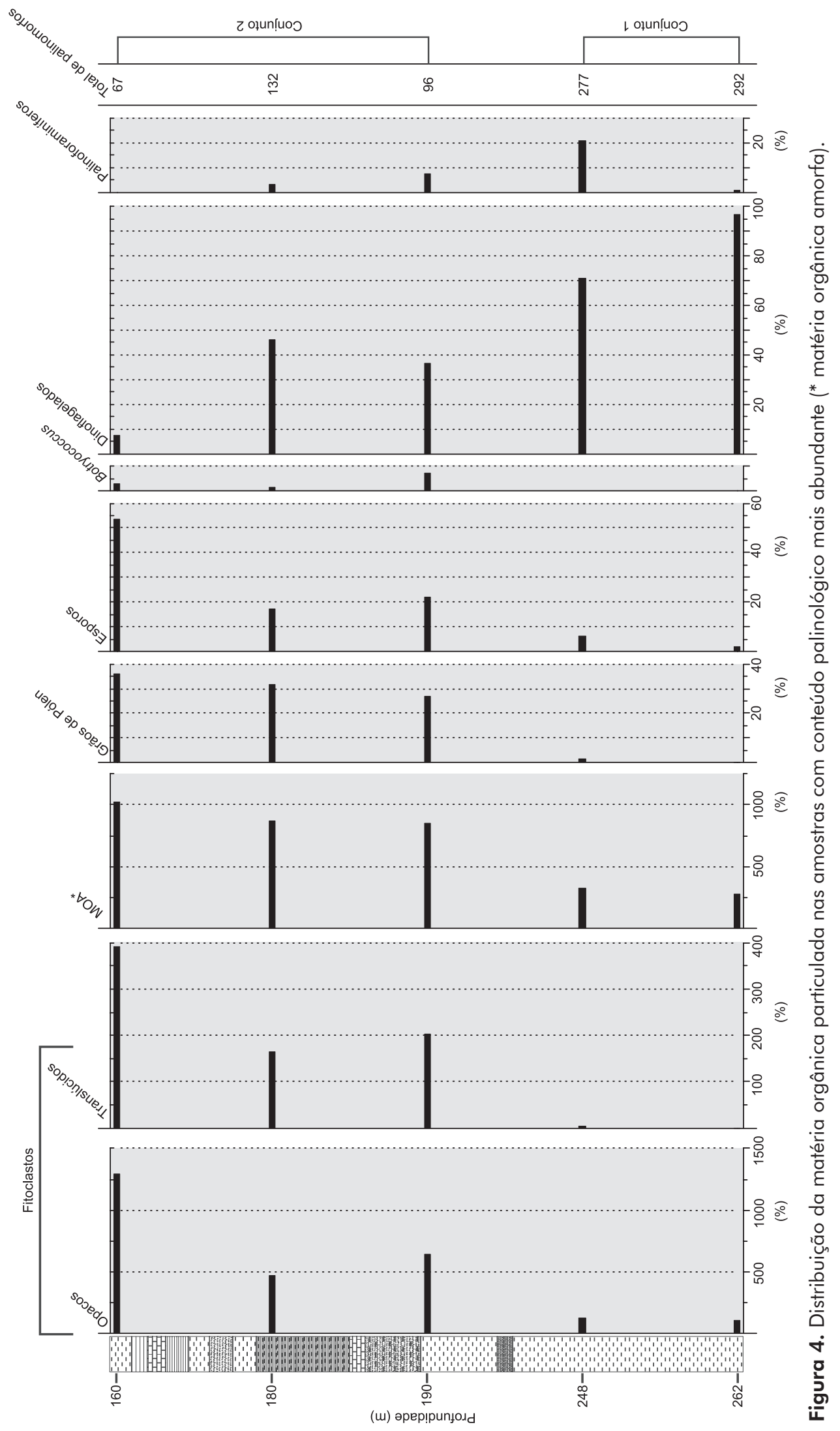


Considerando a presença significativa de dinoflagelados nas duas amostras, esse conjunto é interpretado como representante de condições marinhas, em ambiente nerítico médio a externo. Verifica-se alta concentração de dinoflagelados $(95 \%)$, representados principalmente pelos gêneros gonyaulacoides Lingulodinium, Nematosphaeropsis, Spiniferites indicadores de ambiente marinho. Particularmente, o gênero Nematosphaeropsis é característico de ambientes de plataforma externa e oceânico (Wrenn, 1988). A presença quase que contínua de argilas nesse intervalo estratigráfico também sugere condições paleobatimétricas abaixo do nível de ondas normais, fora do domínio de tempestades.

Esta interpretação é reforçada pela presença de palinoforaminíferos, cuja alta frequência no intervalo é indicativa de ambientes plataformais mais abertos. Na Bacia de Sergipe, Ferreira (2004) registrou altas concentrações desses palinofósseis, indicativos de condições mais distais da linha de costa (ambiente nerítico externo/batial superior).

\section{Conjunto 2 (amostras 160 a 190 m de profundidade)}

Neste intervalo ocorre uma contribuição mais efetiva dos elementos continentais do que nos níveis subjacentes, o que é reforçado pela maior frequência de fitoclastos opacos e translúcidos. Palinomorfos continentais apresentam as maiores porcentagens no espectro palinológico, com grãos de pólen entre $25 \%$ a $35 \%$, esporos $22 \%$ a $55 \%$ e Botryococcus $7 \%$ a $3 \%$. Esses constituintes sofrem leve queda relativa de abundância na amostra a $180 \mathrm{~m}$, contudo com valores sempre superiores com relação às amostras do conjunto 1 . Dinoflagelados estão sempre presentes, mas, por outro lado, apresentam tendência de diminuição em frequência.

$\mathrm{O}$ aumento de elementos continentais a partir da amostra a $190 \mathrm{~m}$ (fitoclastos, esporomorfos), juntamente com a ocorrência de algas dulciaquícolas (Botryococcus), é interpretado como uma ligeira queda no nível relativo do mar, gradando para um ambiente nerítico interno. Essa interpretação é corroborada pela queda acentuada na frequência de dinoflagelados e palinoforaminíferos, com ausência destes últimos na amostra de topo do conjunto 2. A presença comum de areias na parte superior da coluna também apoia esta interpretação, indicativas de condições mais proximais.

Os dinoflagelados peridinioides Quinquecuspis concreta, Selenopemphix nephroides, Selenopemphix dionaeacysta e Selenopemphix quanta se destacam a $180 \mathrm{~m}$. A predominância destes táxon indica condições costeiras com produtividade relativamente mais alta que na parte inferior da coluna estudada.

A vegetação continental de áreas abertas está representada por táxons herbáceos e arbustivos (Asteraceae,
Poaceae), enquanto aqueles da vegetação extrarregional são representados pelas Podocarpaceae.

\section{Idade}

O posicionamento biocronoestratigráfico do material analisado foi baseado na amplitude estratigráfica de determinadas espécies de cistos de dinoflagelados conforme reportado na literatura especializada (Figura 5). Complementadas com as bases de dados TAXON (R.L. Ravn, comunicação pessoal, 2003) e Palynodata (2006). Para calibração cronoestratigráfica foram utilizadas as idades, sintetizadas na Tabela 3 estipuladas por Berggren et al. (1995). Vale ressaltar que, considerando as modificações propostas para a subdivisão do Neógeno, com a inclusão do Gelasiano na base do Pleistoceno, as amplitudes de algumas espécies apontadas por Berggren et al. (1995) como alcançando até o topo do Gelasiano (com indicações de idades absolutas), são reposicionadas aqui como equivalentes à porção basal do Pleistoceno (Figura 5).

Considerando a amplitude estratigráfica em outras bacias dos táxons selecionados apresentados na Figura 5, e a interpretação dos bioeventos da Tabela 3 sugeriu-se diferentes idades entre o Mioceno e o Pleistoceno inferior (Gelasiano) para a maioria das amostras, sendo a mais superior posicionada indiferenciadamente entre o Mesomioceno e o Quaternário.

As espécies de dinoflagelados Selenopemphix brevispinosa e Spiniferites bulloideus têm seus níveis de aparecimento no registro geológico durante o Mioceno inferior, enquanto Lejeunecysta globosa e Lejeunecysta hyalina têm seus níveis de extinção no Mioceno superior (Figura 5). O conjunto das espécies identificadas nas amostras basais (262 m e $248 \mathrm{~m}$ ) permite atribuir uma idade correspondente ao Mioceno, sem especificação do andar.

A ocorrência, no mesmo nível estratigráfico das espécies Nematosphaeropsis rigida e Selenopemphix quanta indicaria, para a amostra a $190 \mathrm{~m}$ de profundidade, idade entre o Mesomioceno ao Recente. Conforme análise da literatura, Quinquecuspis concreta ocorre a partir do Neomioceno, enquanto o último registro de $S$. dionaeacysta é apontado para o Gelasiano, restringindo a idade das amostras a 190 e $180 \mathrm{~m}$ entre o Mesomioceno e o Gelasiano entre (Figura 5).

A ocorrência concomitante dos dinoflagelados Lejeunecysta oliva, Lejeunecysta sabrina e Spiniferites mirabilis na amostra $160 \mathrm{~m}$ de profundidade permite sugerir idade entre o Neoplioceno e o Recente para este nível.

\section{Comparação dos resultados}

O poço 2-CA-1-RS foi alvo de diversos estudos micropaleontológicos, com base em diferentes grupos, com 


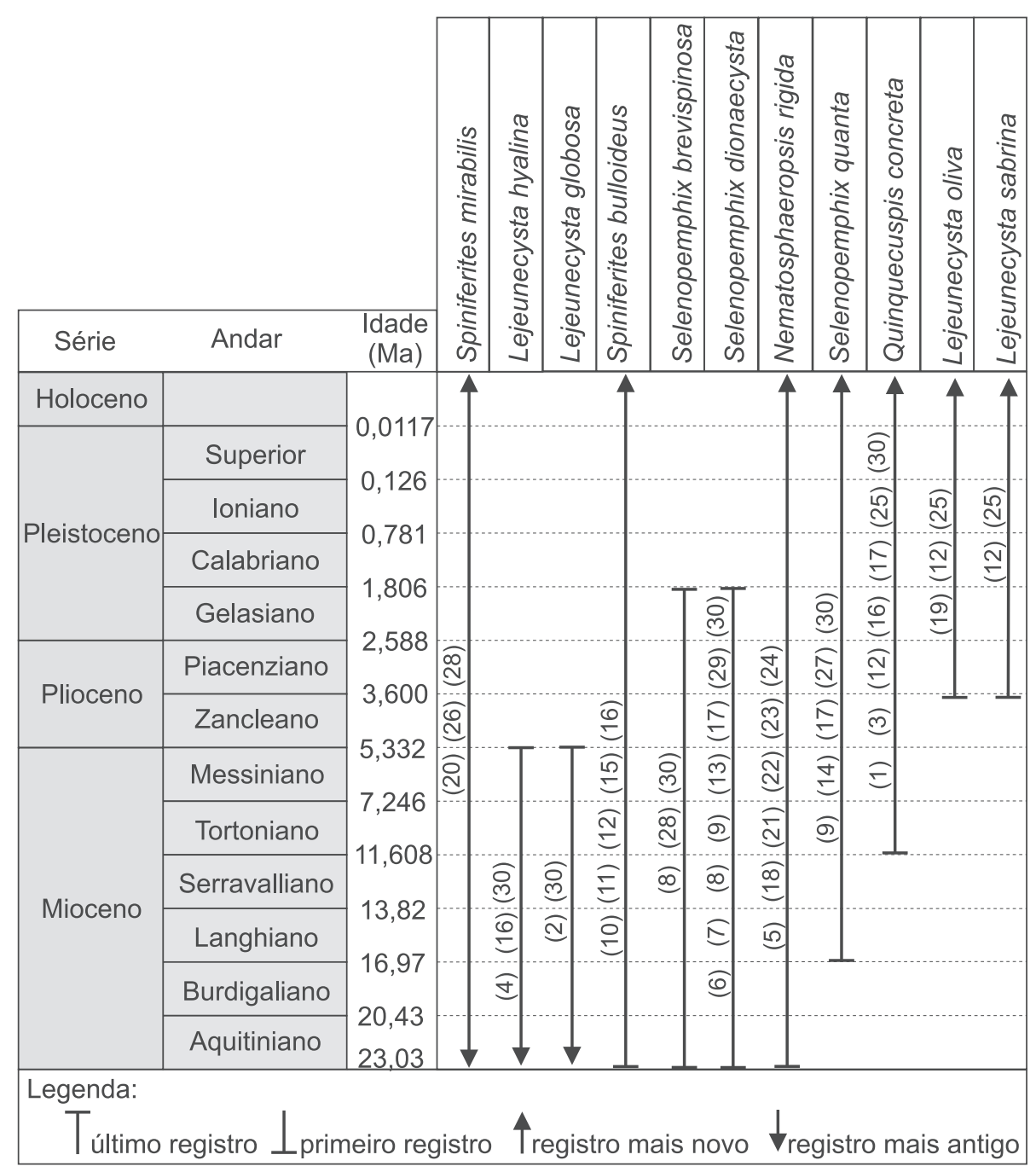

Figura 5. Registros prévios da amplitude estratigráfica de espécies selecionadas identificadas nas amostras utilizadas neste trabalho do poço 2-CA-1-RS. Dados compilados das seguintes publicações: 1. Harland (1977) (Mar do Norte, Inglaterra); 2. Biffi e Grignani (1983) (Delta do Niger, Nigéria); 3. Brown e Downie (1985) (Atlântico Norte, Sudoeste da Irlanda); 4. Williams e Bujak (1985) (Bacias européias); 5. Wrenn (1988) (Golfo do México, Flórida); 6. Head, Norris e Mudie (1989a) (Mar do Labrador, Atlântico Norte); 7. Head, Norris e Mudie (1989b) (Mar do Labrador, Atlântico Norte); 8. Head, Norris e Mudie (1989c) (Bacia de Bafin, Atlântico Norte); 9. Harland (1992) (Mar do Norte, Inglaterra); 10. McMinn (1992a) (Leste do Oceano Índico); 11. McMinn (1992b) (Bacia Gippsland, Austrália); 12. de Vernal et al. (1992) (Atlântico Norte); 13. de Verteuil e Norris (1992) (Planície Costeira de Maryland e Virginia, EUA); 14. Head (1993) (Inglaterra); 15. McMinn (1993a) (Grande Barreira de Corais, Austrália); 16. McMinn (1993b) (Margem nordeste australiana, Austrália); 17. de Verteuil (1996) (Plataforma Continental de Nova Jérsei, EUA); 18. Palamarczuk e Barreda (1998) (Província de Chubut, Argentina); 19. Londeix et al. (1999) (Mar Mediterrâneo, Sicília); 20. Williams e Manum (1999) (Mar da Noruega, Noruega); 21 . Aceñolaza (2000) (Formação Paraná, Argentina); 22. Barreda e Palamarczuk (2000a) (Golfo San Jorge Província de Santa Cruz, Argentina); 23. Barreda e Palamarczuk (2000b) (Costa da Patagônia e Plataforma continental argentina, Argentina); 24. Palamarczuk e Barreda (2000) (Plataforma Continental Argentina, Patagônia); 25. Marret et al. (2001) (Golfo do Alaska); 26. Torricelli e Biffi (2001) (Norte da Tunísia); 27. Kurita e Obuse (2003) (Japão); 28. Helenes e Cabrera (2003) (Leste da Venezuela); 29. Williams et al. (2004) (Global); 30. Helenes, Carreño e Carrillo (2009) (Norte do Golfo da Califórnia, México). 
Tabela 3. Distribuição estratigráfica de espécies índices registradas e respectivas idades conforme Berggren et al. (1995).

\begin{tabular}{|c|c|c|}
\hline $\begin{array}{l}\text { Prof. } \\
(\mathrm{m})\end{array}$ & Síntese da distribuição estratigráfica & Cronoestratigrafia \\
\hline 160 & $\begin{array}{l}\text { Lejeunecysta oliva (idade: } 3,58-0 \mathrm{Ma}) ; \\
\text { Lejeunecysta sabrina }(3,58-0 \mathrm{Ma}) \text {; Spiniferites mirabilis }(33,7-0 \mathrm{Ma})\end{array}$ & $\begin{array}{l}\text { Plioceno superior a Recente } \\
\qquad(3,58-0 \mathrm{Ma})\end{array}$ \\
\hline 180 & $\begin{array}{l}\text { Selenopemphix dionaeacysta }(20,5-1,77 \mathrm{Ma}) \\
\text { Quinquecuspis concreta } \\
(11,2-0 \mathrm{Ma})\end{array}$ & $\begin{array}{l}\text { Mioceno superior a Pleistoceno inferior } \\
\qquad(11,2-1,77 \mathrm{Ma})\end{array}$ \\
\hline 190 & $\begin{array}{l}\text { Nematosphaeropsis rigida }(23,8-0 \mathrm{Ma}) \\
\text { Selenopemphix quanta }(16,4-0 \mathrm{Ma})\end{array}$ & $\begin{array}{l}\text { Mioceno médio Recente } \\
(16,4-0 \mathrm{Ma})\end{array}$ \\
\hline 248 & $\begin{array}{l}\text { Lejeunecysta globosa }(33,7-5,32 \mathrm{Ma}) \\
\text { Lejeunecysta hyalina }(54,8-5,32 \mathrm{Ma})\end{array}$ & $\begin{array}{c}\text { Mioceno } \\
(23,8-5,32 \mathrm{Ma})\end{array}$ \\
\hline 262 & $\begin{array}{l}\text { Spiniferites bulloideus }(23,8-0 \mathrm{Ma}) \\
\text { Selenopemphix brevispinosa }(23,8-1,77 \mathrm{Ma})\end{array}$ & $\begin{array}{c}\text { Mioceno } \\
(23,8-5,32 \mathrm{Ma})\end{array}$ \\
\hline
\end{tabular}

resultados ligeiramente distintos para determinados níveis (Figura 6). O intervalo entre $265 \mathrm{~m}$ e $188 \mathrm{~m}$ foi posicionado no Mioceno com base no exame de foraminíferos realizado por Closs (1970). Uma idade miocena foi confirmada com base em ostracodes para o intervalo entre 262 e 248 m (Sanguinetti, 1974, 1980; Ornellas, 1981), ainda que indiferenciada, proposição aceita e utilizada nas reconstruções paleoambientais por Carreño, Coimbra e Carmo $(1997,1999)$.

Os cistos de dinoflagelados identificados indicam idade miocena para a amostra a $248 \mathrm{~m}$ de profundidade, que encontra apoio nos dados advindos da fauna de ostracodes e foraminíferos (Closs, 1970; Sanguinetti, 1974, 1980; Ornellas, 1981). A associação de L. globosa (Oligoceno-Mioceno superior) e L. hyalina (Eoceno-Mioceno superior) nessa profundidade e $S$. bulloideus (Mioceno-Recente) e S. brevispinosa (Mioceno-Plioceno) na amostra a 262 $\mathrm{m}$, restringem esse trecho basal no Mioceno, correspondente ao conjunto 1 .

Para a porção superior do poço, respectiva ao conjunto 2, verifica-se maior controvérsia. Closs (1970) posicionou o intervalo entre 170 - $0 \mathrm{~m}$ do poço no Pleistoceno, enquanto Ornellas (1981) registrou a base do Pleistoceno à 238,60 m. O último registro de $S$. dionaeacysta (Mioceno-Pleistoceno inferior) e o primeiro registro de $Q$. concreta (Mioceno superior-Recente) indicam idade entre Neomioceno e o Pleistoceno inferior para o nível a $180 \mathrm{~m}$ de profundidade (Figura 6), coincidindo com a atribuição de Closs (1970). Os dados aqui obtidos indicam uma amplitude biocronoestratigráfica entre o Plioceno superior e o Recente para a amostra a $160 \mathrm{~m}$ de profundidade, que é cor- roborada pela presença de Retistephanocolpites gracilis, registrada em depósitos entre o Mioceno médio e o Plioceno de bacias sedimentares brasileiras (Regali, Uesugui, Santos, 1974a, 1974b; Garcia et al., 2008).

Segundo Gomide (1989) a Zona N720 de nanofósseis calcários foi identificada nos níveis mais superiores do poço, aproximadamente a 69 de profundidade, marcando a base do Pleistoceno. Abaixo dessa profundidade não há informações sobre nanofósseis calcários. As zonas imediatamente mais antigas foram estendidas por inferência pelo autor a partir de outros poços adjacentes até o poço 2-CA1-RS (vide Figura 5 de Gomide, op. cit.), levando à interpretação que nos níveis mais inferiores a $69 \mathrm{~m}$ associações pliocênicas e miocênicas poderiam estar presentes.

Em termos paleoambientais, de modo geral, os resultados indicam natureza marinha para os depósitos estudados, com variações significativas da base para o topo, o que permitiu o registro de dois conjuntos palinológicos, com significado paleoambiental. O mais basal, conjunto 1 , reflete condições mais distais, em mar aberto, enquanto o conjunto 2 é interpretado como marinho mais proximal. A natureza marinha para esses depósitos já havia sido indicada com base em foraminíferos e ostracodes (Closs, 1970; Sanguinetti, 1974, 1980; Ornellas, 1981; Carreño, Coimbra, Carmo, 1999). A tendência regressiva detectada entre o conjunto 1 e 2 já havia sido observada por Ornellas (1981), com base nas associações de ostracodes.

O predomínio de cistos gonyaulacoides (Lingulodinium, Nematosphaeropsis, Spiniferites) nas amostras basais $(262$ e $248 \mathrm{~m})$ sugere ambiente marinho franco, nerítico, de águas quentes (Matsuoka, 1992; Edwards e Andrle, 


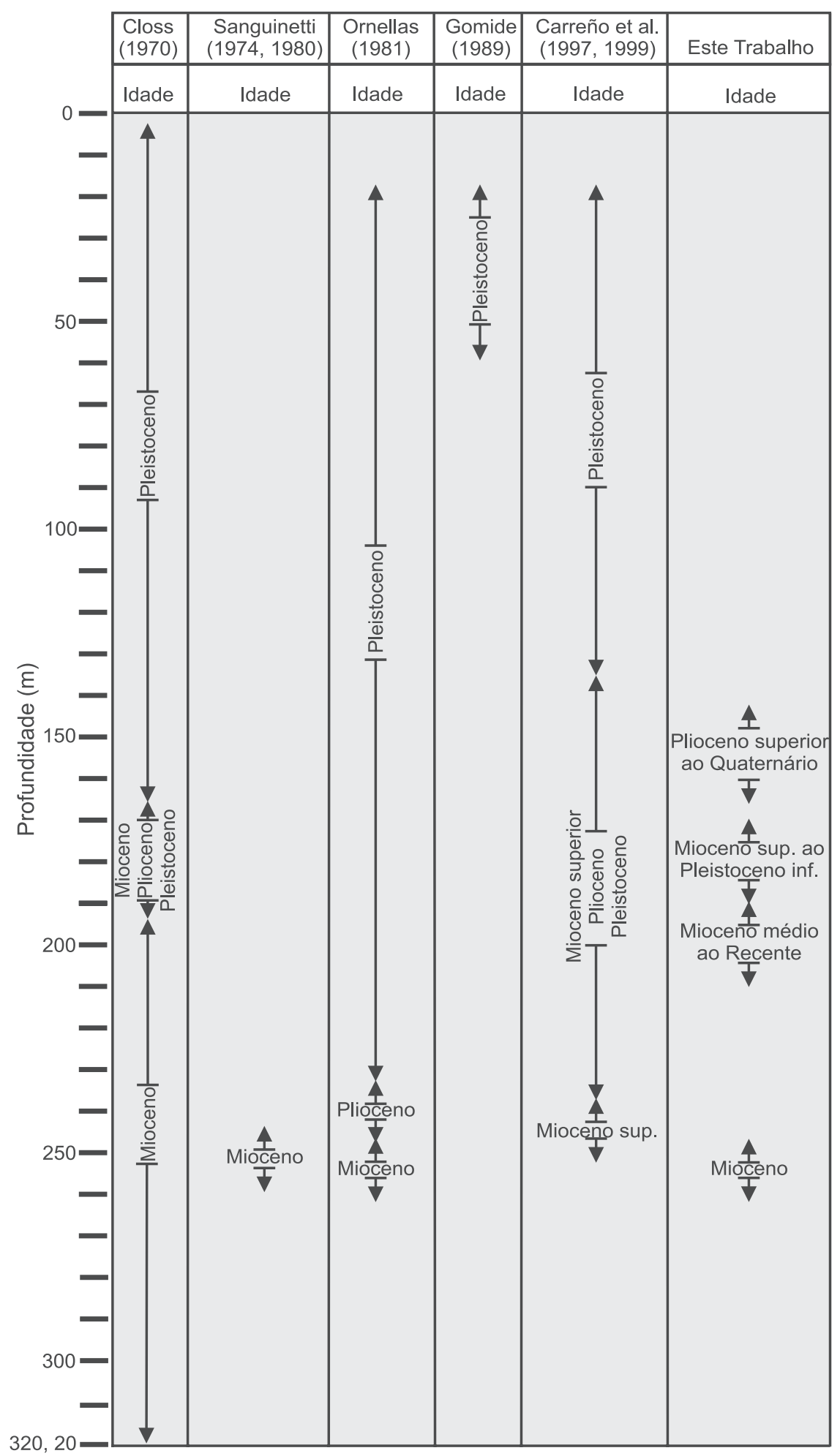

Figura 6. Quadro comparativo dos resultados bioestratigráficos entre os diversos trabalhos realizados no poço 2-CA-1-RS. 
1992), corroborando resultados com ostracodes (Sanguinetti, 1980) para o intervalo. Para Carreño, Coimbra e Carmo (1999), as associações de ostracodes registradas no intervalo entre 248,7 e $238,6 \mathrm{~m}$ refletem as incursões da corrente fria das Malvinas, com presença escassa desses microfósseis, de características de mar raso. Acima desses níveis, as associações de ostracodes foram interpretadas como indicativas de ambientes mixoalinos.

\section{CONCLUSÕES}

Os resultados alcançados demonstraram variações paleoambientais no intervalo analisado, com tendência geral regressiva a partir do Neomioceno, em conformidade com outras ferramentas micropaleontológicas. Dados litoestratigráficos (Gonçalves, Oliveira, Motta, 1979) e de estratigrafia de sequência (Fontana, 1996), delineiam uma cunha sedimentar regressiva com pulsos transgressivos para a bacia, verificados até o Holoceno.

Provavelmente, a transgressão miocena verificada está relacionada ao evento transgressivo marinho que atingiu áreas mais extensas abrangendo a Bacia de Pelotas e áreas adjacentes no Uruguai e Argentina, denominado Mar Entrerriense, com reconstrução esboçada em Martínez e del Rio (2002) e Perea e Martínez (2004).

Embora pouco abundantes, os palinomorfos mostraram eficiência em termos bioestratigráficos, com presença de espécies-guias significativas. Os dois conjuntos palinológicos identificados no trecho onde palinomorfos são mais frequentes, isto é, entre 262 e $160 \mathrm{~m}$, são posicionados no Mioceno ao Recente, respectivamente. As interpretações paleoambientais encontram apoio na literatura disponível a partir de amostras do mesmo poço e no contexto da evolução geral da bacia durante o Neógeno.

Divergências são observadas em termos de posicionamento bioestratigráfico, seja entre os dados de microfósseis calcários entre si, seja comparando-se os dados obtidos nesse trabalho (Figura 6). Contudo, dados de nanofósseis calcários são disponíveis somente para a porção superior do poço $(69-0 \mathrm{~m})$. Para os demais grupos de microfósseis calcários, há que se observar que, embora constituam trabalhos pioneiros, foram realizados há longa data, com carências de revisão sobre seu significado bioestratigráfico.

Os dados palinológicos se somam ao conhecimento geral da sucessão micropaleontológica, se revelando como ferramentas úteis em termos bioestratigráficos e paleoambientais. Contudo, a ausência de zoneamentos disponíveis com cistos de dinoflagelados para o Neógeno ou com esporomorfos para essa porção da margem atlântica e, especialmente para a Bacia de Pelotas, impõe limitação ao posicionamento bioestratigráfico uma vez que não se co- nhece o comportamento geral da sucessão destes microfósseis de parede orgânica nesta porção do Atlântico Sul. Por outro lado, demonstram a necessidade de trabalhos intensivos no tema, focados na identificação de associações palinológicas, na integração com outras ferramentas, para a obtenção de um quadro bioestratigráfico mais completo para a seção na bacia.

\section{AGRADECIMENTOS}

Os autores agradecem à PETROBRAS S.A. pela cedência das amostras ao PPGGEO e a FAPERGS (Processo 1012119) pela concessão de recursos financeiros. Este trabalho constitui parte da dissertação de mestrado do primeiro autor, bolsista $\mathrm{CNPq}$, junto ao PPGGEO.

\section{REFERÊNCIAS}

ACEÑOLAZA, F. G. La Formacion Paraná (Mioceno médio): estratigrafia, distribución regional y unidades equivalentes. In: ACEÑOLAZA, F. G.; HERBST, R. (Ed.). El Neógeno de Argentina. Tucumán: INSUGEO, 2000. p. 9-27. (Serie Correlación Geológica).

ANJOS-ZERFAS, G. S.; SOUZA, P. A.; CHEMALE JR, F. Biocronoestratigrafia da Bacia de Pelotas: estado atual e aplicação na geologia do petróleo. Revista Brasileira de Geociências, v. 38, n. 2, p. 47-62, 2008. (Suplemento).

ARAI, M.; MASURE, E.; LEMOS, V. B. Occurrence of a high-diversity Aptian microphytoplanktonic assemblage in Pelotas Basin (Southern Brazil): its implication for the Early Cretaceous history of the South Atlantic. In: SIMPÓSIO DO CRETÁCEO DO BRASIL. 7., 2006, Serra Negra. Boletim de resumos... Rio Claro: UNESP, 2006. p. 12.

ARAI, M. Sucessão das associações de Dinoflagelados (Protista, Pyrrhophyta) ao longo das colunas estratigráficas do Cretáceo das bacias da margem continental brasileira: uma análise sob ponto de vista paleoceanográfico paleobiogeográfico. 2007. 170 f. Tese (Doutorado) - Instituto de Geociências, Universidade Federal do Rio Grande do Sul, Porto Alegre, 2007.

BARREDA, V.; PALAMARCZUK, S. Palinoestratigrafía de depósitos del Oligoceno tardio-Mioceno en el área sur del Golfo San Jorge, provincia de Santa Cruz, Argentina. Ameghiniana, v. 37, n. 1, p. 103-117, 2000a.

BARREDA, V.; PALAMARCZUK, S. Estudio palinoestratigráfico del Oligoceno tardío-Mioceno en 
secciones de la costa patagônica y plataforma continental argentina. In: ACEÑOLAZA, F. G.; HERBST, R. El Neógeno de Argentina. Tucumán: INSUGEO, 2000b. p. 103-138. (Serie Correlación Geológica).

BAUERMANN, S. G.; BEHLING, H.; MACEDO, R. B. Biomas regionais e evolução da paisagem no Rio Grande do Sul com base em paleopalinologia. In: RIBEIRO, A. M.; BAUERMANN, S. G.; SCHERER, C. S. Quaternário do Rio Grande do Sul integrando conhecimentos. Porto Alegre: SBP, 2009. p. 81-93. (Monografias da Sociedade Brasileira de Paleontologia).

BERGGREN, W. A.; KENT, D. V.; SWISHER, C. C.; AUBRY, M. P. A revised cenozoic geochronology and chronostratigraphy. In: BERGGREN, W. A.; KENT, D. V.; AUBRY, M. P.; HARDENBOL, J. Geochronology, Time Scales and stratigraphic correlation. Tulsa: SEPM, 1995. p. 129-212. (Special Publication, 54).

BIFFI, V.; GRIGNANI, D. Peridiniod dinoflagellate cyst from the Oligocen of Niger Delta, Nigeria. Micropaleontology, v. 29, n. 2, p. 126-146, 1983.

BROWN, S.; DOWNIE, C. Dinoflagellate cyst stratigraphy of Paleocene to Miocene sediments from the Goban Spur (sites 548-550, leg 80) In: GRACIANSKY, P. C.; POAG, C. W.; et al., Initial Reports. DSDP, v. 80, p. 643-651, 1985. Disponível em: $<$ http://www.deepseadrilling.org/i reports.htm $>$. Acesso em: 10 mar. 2010.

BUENO, G. V.; ZACHARIAS, A. A.; OREIRO, S. G.; CUPERTINO, J. A.; FALKENHEIN, F. U. H.; NETO, M. A. M. Bacia de Pelotas. Boletim de Geociências Petrobras, v. 15 , n. 2, p. 551-559, 2007.

CARREÑO, A. L.; COIMBRA, J. C.; CARMO, D. A. Bioestratigraphy of the Late Neogene and Quaternary ostracodes in the Pelotas Basin, Southern Brazil. Gaia, v. 14, p. 33-43, 1997.

CARREÑO, A. L.; COIMBRA, J. C.; CARMO, D. A. Late Cenozoic sea level changes evidenced by ostracodes in the Pelotas Basin, southernmost Brazil. Marine Micropaleontology, v. 37, p. 117-129, 1999.

CLOSS, D. Estratigrafia da Bacia de Pelotas, Rio Grande do Sul. Iheringia, n. 3, p. 3-76, 1970.

DAEMON, R. F. Estudo bioestratigráfico preliminar efetuado em sedimentos neogênicos do poços 2-PS-1-RS (Palmares do Sul, RS), 2-MO-1-RS (Mostardas, RS) e
2-CI-1 (Cassino, RS). Relatório 390, Petrobrás. Distrito de Exploração do Sul, 1969. 17 p. (não publicado).

DIAS, J. L.; SAD, A. R. E.; FONTANA, R. L.; FEIJÓ, F. J. Bacia de Pelotas. Boletim de Geociências Petrobras, v. 8, n.1, p. 235-245, 1994.

DE VERNAL, A.; MUDE, P. J.; HARLAND, R.; MORZADEC-KERFOURN, M. T.; TURON, J.; WRENN, J. H. Quaternary organic-walled dinoflagellate cysts of the North Atlantic Ocean and adjacent seas: ecostratigraphy and biostratigraphy. In: HEAD, M. J.; WRENN, J. H. (Ed.).Neogene and Quaternary Dinoflagellate Cyst and Acritarchs. Dallas: American Association of Stratigraphic Palynologists Foundation, 1992. p. 289-328.

DE VERTEUIL, L. Data report: upper Cenozoic dinoflagellate cysts from the continental slope and rise off New Jersey. In: MOUNTAIN, G. S.; MILLER, K. G.; BLUM, P.; POAG, C. W.; TWICHELL, D. C.; et al. Proceedings of the Ocean Drilling Program, Scientific Result, v. 150, p. 439-454, 1996. Disponível em: <http://www-odp.tamu.edu/publications $>$. Acesso em: 04 abr. 2009.

DE VERTEUIL, L.; NORRIS, G. Miocene Protoperidiniacean dinoflagellate cyst from the Meryland and Virginia coastal plain. In: HEAD, M. J.; WRENN, J. H. (Ed.). Neogene and Quaternary Dinoflagellate Cyst and Acritarchs. Dallas: American Association of Stratigraphic Palynologists Foundation, 1992. p. 391-430.

EDWARDS, L. E.; ANDRLE, V. A. S. Distribution of selected dinoflagellate cysts in modern marine sediments. In: HEAD, M. J.; WRENN, J. H. Neogene and Quaternary Dinoflagellate Cyst and Acritarchs. Dallas: American Association of Stratigraphic Palynologists Foundation, 1992. p. 259-288.

FERREIRA, E. P. Palinoestratigrafia e caracterização de paleoambientes da seção paleocênica-eocênica da Bacia de Sergipe. 2004. 2v. Tese (Doutorado) - Instituto de Geociências, Universidade Federal do Rio de Janeiro, Rio de Janeiro, 2004.

FISCHER, T. V. Posicionamento bioestratigráfico e paleoambientes de seção selecionada do Paleógeno Inferior da Bacia de Pelotas (RS), com base em Palinologia. 2008. Monografia (Trabalho de Conclusão de Curso em Geologia) - Instituto de Geociências, Universidade Federal do Rio Grande do Sul, Porto Alegre, 2008. 
FISCHER, T. V.; ARAI, M.; SOUZA, P. A. Biestratigrafia com base em dinocistos (divisão Dinoflagellata, classe Dinophyceae) Paleógeno do poço 2-RSS-1. In: CONGRESSO BRASILEIRO DE GEOLOGIA, 44, 2008a. Curitiba. Anais... Curitiba: SBG, 2008. 1 CD-ROM.

FISCHER, T. V.; ARAI, M.; SOUZA, P. A. Palinologia: distribuição quantitativa da matéria orgânica particulada e paleoambientes da transição entre o Cretáceo e o Terciário do poço 2-RSS-1(Bacia de Pelotas, RS). In: SIMPÓSIO BRASILEIRO DE PALEOBOTÂNICA E PALINOLOGIA, 12., 2008b. Florianópolis. Boletim de resumos... Florianópolis: ALPP, 2008. p. 74.

FISCHER, T. V.; PREMAOR, E.; ARAI, M.; SOUZA, P. A. Palinologia da Bacia de Pelotas: dados preliminares da seção paleocênica. In: CONGRESSO BRASILEIRO DE PALEONTOLOGIA, 20., 2007, Búzios. Anais... Búzios: SBP, 2007, p. 232.

FONTANA, R. L. Geotectônica e sismoestratigrafia da Bacia de Pelotas e Plataforma de Florianópolis. 1996. 2 v. Tese (Doutorado) - Instituto de Geociências, Universidade Federal do Rio Grande do Sul, Porto Alegre, 1996.

GARCIA, M. J.; BISTRICHI, C. A.; SAAD, A. R.; CAMPANHA, V. A.; OLIVEIRA, P. E. Stratigraphy and paleoenvironments of the Tanque Basin, Southeastern Brazil. Revista Brasileira de Paleontologia, v. 11, n. 3, p. 147-168, 2008.

GONÇALVES, A; OLIVEIRA, M. A. M.; MOTTA, S. O. Geologia da Bacia de Pelotas e da Plataforma de Florianópolis. Boletim de Geociências Petrobras, v. 22, n. 3, p. 157-174, 1979.

GOMIDE, J. Bacia de Pelotas biocronoestratigrafia baseada em nanofósseis calcários. In: CONGRESSO BRASILEIRO DE PALEONTOLOGIA, 11., 1989, Curitiba. Anais... Curitiba, 1989. p. 339-351.

GRIMM, E. C. Coniss: a Fortran 77 program for stratigraphically constraining cluster analysis by the method of the incremental sum of square. Computer \& Geosciences, v. 13, p.13-35, 1987.

GRIMM, E. C. Tilia and Tiliagraph: PC spreadsheet and graphics software for pollen data. INQUA, Commission for the Study of the Holocene, Working Group on DataHandling Methods, 1990. p. 5-7, (Newsletter 4).
HARLAND, R. Recent and Late Quaternary (Flandrian and Devensian) Dinoflagellate cysts from marine continental shelf sediments around the British isles. Paleontographica Abt. B. Stuttgart, v. 164, p. 87-126, 1977.

HARLAND, R. Dinoflagellate cysts of the Quaternary system. In: POWELL, A. J. A Stratigraphic Index of Dinoflagellate Cysts. London: Chapman and Hall, 1992. p. 253-273.

HEAD, M. J. Dinoflagellates, sporomorphs and other palynomorphs from the Upper Pliocene St. Erth Beds of Cornwall, Southwestern England. Journal of Paleontology, v. 67, n. 3, p. 1-49, 1993.

HEAD, M. J.; NORRIS, G.; MUDIE, P. J. Palynology and dinocyst stratigraphy of the upper Miocene and lowermost Pliocene, ODP Leg 105, Site 646, Labrador Sea. In: SRIVASTAVA, S. P.; ARTHUR, M.; CLEMENT, B.; et al. Proceedings of the Ocean Drilling Program, Scientific Result, v. 105, p. 423-451, 1989a. Disponível em: <http:// www-odp.tamu.edu/publications $>$. Acesso em: 04 abr. 2009.

HEAD, M. J.; NORRIS, G.; MUDIE, P. J. New species of dinocysts and a new species of acritarch from the upper Miocene and lowermost Pliocene, ODP Leg 105, Site 646, Labrador Sea. In: SRIVASTAVA, S. P.; ARTHUR, M.; CLEMENT, B.; et al. Proceedings of the Ocean Drilling Program, Scientific Result, v. 105, p. 453-466, 1989b. Disponível em: $<$ http://www-odp.tamu.edu/publications $>$. Acesso em: 04 abr. 2009.

HEAD, M. J.; NORRIS, G.; MUDIE, P. J. Palynology and dinocyst stratigraphy of the Miocene in ODP Leg 105, Hole 645E, Baffin Bay. In: SRIVASTAVA, S. P.; ARTHUR, M.; CLEMENT, B.; et al. Proceedings of the Ocean Drilling Program, Scientific Result, v. 105, p. 467-514, 1989c. Disponível em: <http://www-odp. tamu.edu/publications $>$. Acesso em: 04 abr. 2009.

HELENES, J.; CABRERA, D. Oligocene-Miocene Palynomorph assemblages from eastern Venezuela. Palynology, v. 27, p. 5-25. 2003.

HELENES, J.; CARREÑOO, A. L.; CARRILlO, R. M. Middle to late Miocene chronostratigraphy and development of the northern Gulf of California. Marine Micropaleontology, v. 72, n. 1-2, p. 10-25. 2009.

HERMANY, G. Paleoecologia do sistema PinguelaPalmital-Malvas, Holoceno da Bacia de Pelotas, RS, Brasil: uma abordagem focada na utilização de diatomáceas 
(Bacillariophyta) como descritores paleoambientais. 2009. Tese (Doutorado) - Instituto de Geociências, Universidade Federal do Rio Grande do Sul, Porto Alegre, 2009.

KLEY, A. S. Reconstituição paleoambiental e paleogeográfica do Cenozóico na Bacia de Pelotas: Estudo do poço 2-TG-96-RS (Capão da Canoa, RS, Brasil). 2007. Monografia (Trabalho de Conclusão de Curso em Geografia) - Instituto de Geociências, Universidade Federal do Rio Grande do Sul. Porto Alegre, 2007.

KURITA, H.; OBUSE, A. Middle Miocene-Uppermost Lower Pliocene dinoflagellate cyst biostratigraphy, ODP leg 186 hole 1151A, off Sanriku Coast of Northern Japan, Northwestern Pacific. In: SUYEHIRO, K.; SACKS, I. S.; ACTON, G. D.; ODA, M.; et al. Proceedings of the Ocean Drilling Program, Scientific Result, v. 186, p. 1-19, 2003. Disponível em: <http://www-odp.tamu.edu/publications $>$. Acesso em: 05 jun. 2009.

LIMA, M. R.; DINO, R. Palinologia de amostras da Bacia de Bonfim, terciário do estado de São Paulo, Brasil. Boletim IG-USP. São Paulo, v. 15, p. 1-11. 1984.

LIMA, M. R.; AMADOR, E. S. Análise palinológica de sedimentos da formação Resende, Terciário do estado do Rio de Janeiro, Brasil. In: CONGRESSO BRASILEIRO DE PALEONTOLOGIA, 8., 1983. Rio de Janeiro. Coletânea... Rio de Janeiro: MME-DNPM, 1985. p 371-378.

LIMA, M. R.; ANGULO, R. J. Descoberta de microflora em um nível linhítico da Formação Alexandra, Terciário do Estado do Paraná, Brasil. Anais da Academia Brasileira de Ciências, v. 62, n. 4, p. 357-371. 1990.

LIMA, M. R.; MELO, M. S.; COIMBRA, A. M. Palinologia de sedimentos da Bacia de São Paulo, Terciário do estado de São Paulo, Brasil. Revista do Instituto Geológico, v. 12, n. 1/2, p. 7-20, 1991.

LIMA, M. R.; RICCOMINI, C.; SOUZA, P. A. Palinologia de folhelhos do Gráben de Casa de Pedra, Terciário do estado do Rio de Janeiro, Brasil. Acta Geológica Leopoldensia, v. 39, p. 485-504, 1994.

LONDEIX, L.; BENZAKOUR, M.; DE VERNAL, A.; TURON, J. L.; SUC, J.P. Late Neogene dinoflagellate cyst assemblages from the Strait of Sicily, Central Mediterranean Sea: paleoecological and biostratigraphical implications. In: WRENN, J. H.; et al. The Pliocene:Time of Change. Dallas: American Association of Stratigraphic Palynologists Foundation, 1999. p. 65-91. (Contribution Series).
MARRET, F.; de VERNAL, A.; PEDERSEN, T. F.; McDONALD, D. Middle Pleistocene to Holocene palynostratigraphy of Ocean Drilling Program Site 887 in the Gulf of Alaska, northeastern North Pacific. Canadian Journal of Earth Sciences, Canada, v. 38, p. 373-386, 2001.

MARTÍNEZ, S.; DEL RÍO, C. J. Late Mioce mollusc from the southwestern Atlantic Ocean (Argentina and Uruguay): a paleobiogeographic analysis. Paleogeography, Paleoclimatology, Paleoecology, v. 188, p. 167-187. 2002.

MATSUOKA, K. Species diversity of Modern dinoflagellate cyst in surface sediments around the Japanese islands. In: HEAD, M.J.; WRENN, J. H. (Ed.). Neogene and Quaternary Dinoflagellate Cyst and Acritarchs. Dallas: American Association of Stratigraphic Palynologists Foundation, 1992, p. 33-53.

McMINN, A. Pliocene through Holocene dinoflagellate cyst biostratigraphy of the Gippsland Basin, Australia. In: HEAD, M. J.; WRENN, J. H. (Ed.). Neogene and Quaternary Dinoflagellate Cyst and Acritarchs. Dallas: American Association of Stratigraphic Palynologists Foundation, 1992a, p. 391-430.

McMINN, A. Neogene dinoflagellate distribution in the eastern Indian Ocean from leg, site 765. In: GRADSTEIN, F. M.; LUDDEN, J. N.; et al. Proceedings of the Ocean Drilling Program, Scientific Result, v. 123, p. 429-441, 1992b. Disponível em: < $\underline{\text { http://www-odp.tamu.edu/ }}$ publications >. Acesso em: 04 abr. 2009.

McMINN, A. Quaternary dinoflagellate cyst distribution at site 820, Great Barrier Reef. In: MCKENZIE, J.A.; DAVIES, P.J.; PALMER-JULSON, A.; et al. Proceedings of the Ocean Drilling Program, Scientific Result, v. 133, p. 93-95, 1993a. Disponível em: <http://www-odp.tamu.edu/ publications $>$. Acesso em: 04 abr. 2009.

McMINN, A. Neogene dinoflagellate cyst biostratigraphy from sites 815 and 823, leg 133, northeastern Australian margin. In: MCKENZIE, J.A.; DAVIES, P.J.; PALMERJULSON, A.; et al. Proceedings of the Ocean Drilling Program, Scientific Result, v. 133, p. 97-105, 1993b. Disponível em: $<\underline{\text { http://www-odp.tamu.edu/publications }}>$. Acesso em: 04 abr. 2009.

ORNELLAS, L. P. Os ostracodes e seu significado na interpretação dos eventos cenozóicos na Bacia de Pelotas, RS: transgressões, regressões, paleoecologia e bioestratigrafia. 1981. Tese (Doutorado) - Instituto de 
Geociências, Universidade Federal do Rio Grande do Sul, Porto Alegre, 1981.

PALAMARCZUK, S.; BARREDA, V. Bioestratigrafía en base a quistes de dinoflagelados de la formación Chenque (Mioceno), Provincia del Chubut, Argentina. Ameghiniana, v. 35, n. 2, p. 415-426. 1998.

PALAMARCZUK, S.; BARREDA, V. Palinología del Paleogeno tardio-Neogeno temprano, pozo Aries $\mathrm{x}-1$, Plataforma Continental Argentina, Terra del Fuego. Ameghiniana, v. 37, n. 2, p. 221-234, 2000.

PALYNODATA INC.; WHITE, J. M. Palynodata Datafile: 2006 version, with Introduction by J.M. White. 2008. 1 CD-ROM (Geological Survey of Canada Open File 5793).

PEREA, D.; MARTÍNEZ, S. Estratigrafia del MiocenoPleistoceno en Litoral Sur-Oeste de Uruguay. In: VEROSLAVSKY, G.; UBILLA, M.; MARTÍNEZ, S. Cuencas sedimentares de Uruguay: Geología, paleontología y recursos naturales. Cenozóico. Montevidéu: DI.R.A.C, 2004. p. 105-124.

PREMAOR, E. Palinologia da Bacia de Pelotas (RS): bioestratigrafia e paleoambientes da seção campaniana no poço 2-RSS-1. 2008. Monografia (Trabalho de Conclusão de Curso em Geologia) - Instituto de Geociências, Universidade Federal do Rio Grande do Sul. Porto Alegre, 2008.

PREMAOR, E.; ARAI, M.; SOUZA, P. A. Considerações paleoambientais sobre as associações de cistos de dinoflagelados do Neocretáceo do poço 2-RSS-1, Bacia de Pelotas, RS, Brasil. In: SIMPÓSIO BRASILEIRO DE PALEOBOTÂNICA E PALINOLOGIA, 12, 2008, Florianópolis. Boletim... Florianópolis: ALPP, 2008, p.167.

PREMAOR, E.; FISCHER, T. V.; ARAI, M.; SOUZA, P. A. Palinologia da Bacia de pelotas: dados preliminares da seção cretácea. In: CONGRESSO BRASILEIRO DE PALEONTOLOGIA, 20., 2007, Búzios. Anais... Búzios: SBP, 2007. p. 231.

REGALI, M. S. P.; UESUGUI, N.; SANTOS, A. S. Palinologia dos sedimentos Meso-Cenozóicos do Brasil. Parte I. Boletim de Geociências Petrobras, v. 17, n. 3, p. 177-191, 1974a.

REGALI, M. S. P.; UESUGUI, N.; SANTOS, A. S. 1974b. Palinologia dos sedimentos Meso-Cenozóicos do Brasil. Parte II. Boletim de Geociências Petrobras, v. 17, n. 4, p. 263-301, 1974b.
SANGUINETTI, Y. T. Tafofaunula de Ostracodes $e$ Bioestratigrafia do Mioceno da Bacia de Pelotas, Rio Grande do Sul. 1974. Tese (Doutorado) - Instituto de Geociências, Universidade Federal do Rio Grande do Sul, Porto Alegre, 1974.

SANGUINETTI, Y. T. Bioestratigrafia (Ostracodes do Mioceno da Bacia de Pelotas, Rio Grande do Sul). Pesquisas, v. 13, p. 7-34, 1980.

SEKIGUCHI, F. B. C. Bioclastos de organismos terrestres e marinhos na praia e plataforma interna do Rio Grande do Sul: natureza, distribuição, origem e significado geológico. 2002. Tese (Doutorado) - Instituto de Geociências, Universidade Federal do Rio Grande do Sul, Porto Alegre, 2002.

SILVA, W. G. Bioestratigrafia e variações relativas do nivel do mar na Planície Costeira do Rio Grande do Sul: estudo da seção neogênica/Quaternária do poço 2-CA-1RS com base em registro palinológico. 2008. Monografia (Trabalho de Conclusão de Curso em Geografia) - Instituto de Geociências, Universidade Federal do Rio Grande do Sul. Porto Alegre, 2008.

SILVA, W. G.; SOUZA, P. A. Palinologia da Bacia de Pelotas: dados inéditos do poço 2-CA-1-RS (Curral Alto, RS) In: SALÃO DE INICIAÇÃO CIENTÍFICA, 20., 2008, Porto Alegre. Livro... Porto Alegre: PROPESQ, 2008. v. 1. p.19.

SILVA, W. G.; SOUZA, P. A.; ARAI, M. Palinologia do Intervalo Neogênico do poço 2-CA-1-RS (Curral Alto, RS) Bacia de Pelotas. In: SIMPÓSIO BRASILEIRO DE PALEOBOTÂNICA E PALINOLOGIA, 12., 2008, Florianópolis. Boletim... Florianópolis: ALPP, 2008, p. 202.

TOMAZELLI, L. J.; VILLWOCK, J. A. O Cenozóico no Rio Grande do Sul: Geologia da Planície Costeira. In: HOLZ, M.; De ROS, L. F.(Ed.) Geologia do Rio Grande do Sul. Porto Alegre: CIGO/UFRGS, 2000. p. 375-406.

TORRICELLI, S.; BIFFI, U. Palynostratigraphy of the Numidian Flysch of Northern Tunisia (Oligocene-Early Miocene). Palynology, v. 25, p. 29-55, 2001.

VILLWOCK, J. A.; TOMAZELLI, L. J. Geologia Costeira do Rio Grande do Sul. Notas Técnicas, v. 8, p. 1-45. 1995.

WILLIAMS, G .L.; BUJAK, J. P. Mesozoic and Cenozoic dinoflagellates. In: BOLLI, H. M.; SAUNDERS, J. B.; PERCH-NIELSEN, K. Plankton Stratigraphy. Cambridge: 
Cambridge University Press, 1985. p. 847-964. (Earth Sciences Series).

WILLIAMS, G. L.; MANUM, S. B. Oligocene-Early Miocene dinocyst stratigraphy of hole 985A (Norwegian Sea) In: RAYMO, M. E.; JANSEN, E.; BLUM, P.; HERBERT, T. D., et al. Proceedings of the Ocean Drilling Program, Scientific Result, v. 162, p. 99-109, 1999. Disponível em: $<$ http://www-odp.tamu.edu/publications $>$. Acesso em: 15 abr. 2009.

WILLIAMS, G. L.; BRINKHUIS, H.; PEARCE, M. A.; FENSOME, R. A.; WEEGINK, J. W. Southern Ocean and global dinoflagellate cyst events compared: index events for the Late Cretaceous-Neogene. In: EXON, N.F.; KENNETT, J.P.; MALONE, M.J., et al. Proceedings of the Ocean Drilling Program, Scientific Result, v. 189, p. 1-98, 2004. Disponível em: <http://www-odp.tamu.edu/ publications $>$. Acesso em: 01 nov. 2007.

WOOD, G. D.; GABRIEL, A. M.; LAWSON, J. C. Palynologycal techniques-processing and microscopy. In: JANSONIUS, J.; MCGREGOR, D. C. Palynology: priciples and applications. Dallas: American Association of Stratigraphic Palynologists Foundation, 1996. v.1, p. 29-50.

WRENN, J. H. Diferentiating species of the dinoflagellate cyst genus Nematosphaeropsis Deflander \& Cookson. Palynology, v. 12, p. 129-150, 1988. 
1

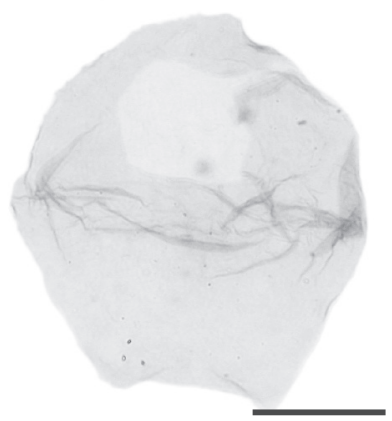

4

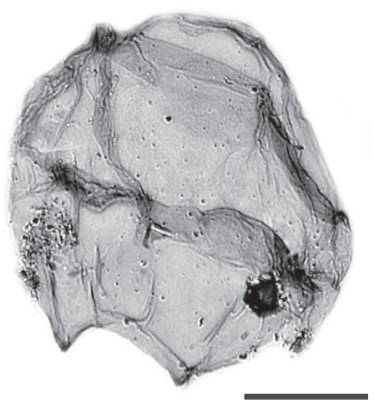

7

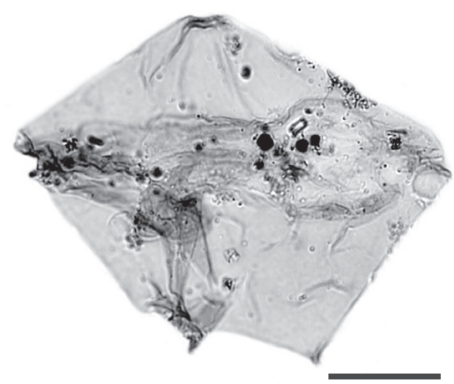

10

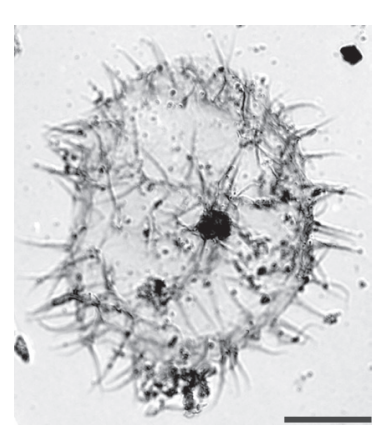

2

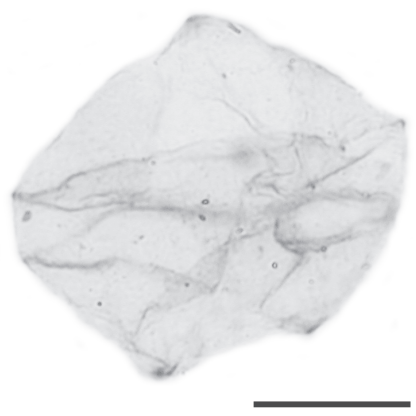

5

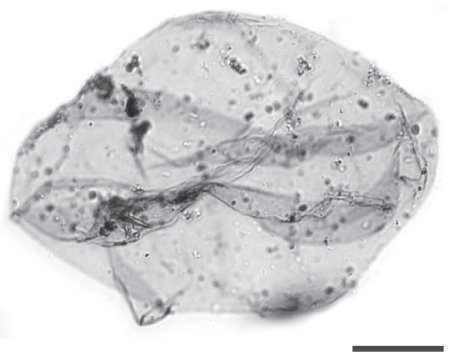

6
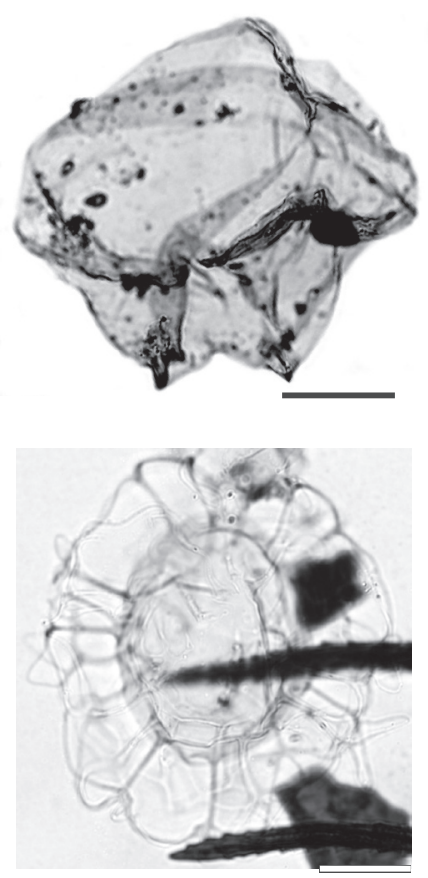

9
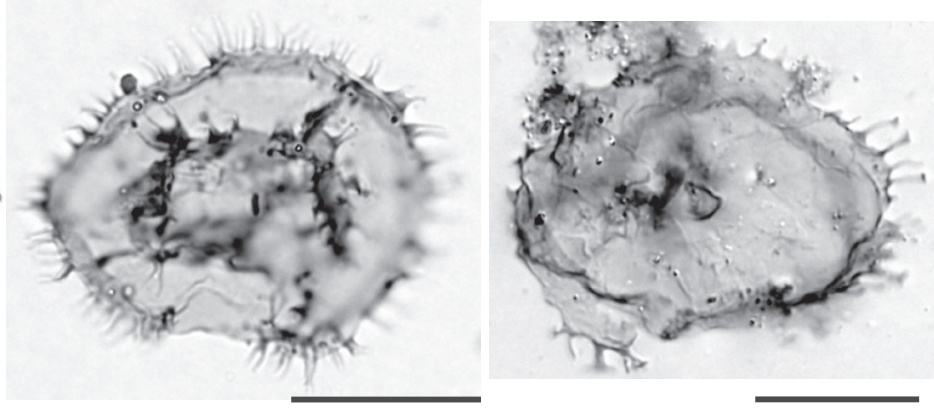

12

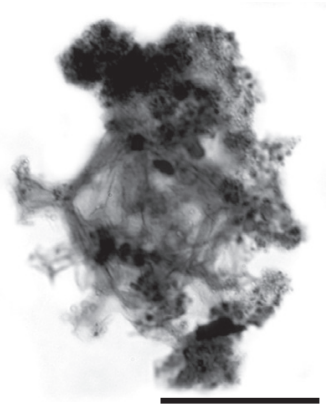

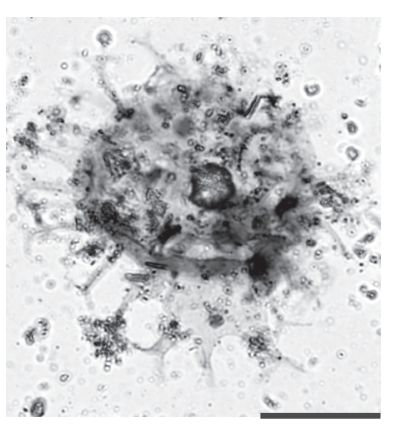

Figura 7. Fotomicrografias de espécimes selecionados. 1. Lejeunecysta globosa Biffi e Grignani 1983 (MP-P 5639, R34-3); 2. Lejeunecysta hyalina (Gerlach 1961) Artzner e Dörhöfer 1978 (MP-P 5638, K44-1); 3. Lejeunecysta oliva (Reid) Turon e Londex 1988 (MP-P 5609, P51); 4. Lejeunecysta sabrina (Reid) Bujak 1984 (MP-P 5610, V37); 5. Lejeunecysta cf. globosa Biffi e Grignani 1983 (MP-P 5617, K41); 6. Nematosphaeropsis rigida Wrenn 1988 (MP-P 5635, N27); 7. Quinquecuspi concreta (Reid 1977) Harland 1977 (MP-P 5616, P30); 8. Selenopemphix brevispinosa Head et al. 1989c (MP-P 5646, S39).; 9. Selenopemphix dionaeacysta Head et al. 1989b (MP-P 5617, R39); 10. Selenopemphix quanta (Bradford 1975) Matsuoka 1985 (MP-P 5617, K35-2); 11. Spiniferites bulloideus Deflandre e Cookson 1955 (MP-P 5650, G49-4); 12. Spiniferites mirabilis (Rossignol 1964) Sarjeant 1970 (MP-P 5621, E48). Escala gráfica: $20 \mu \mathrm{m}$. 
1

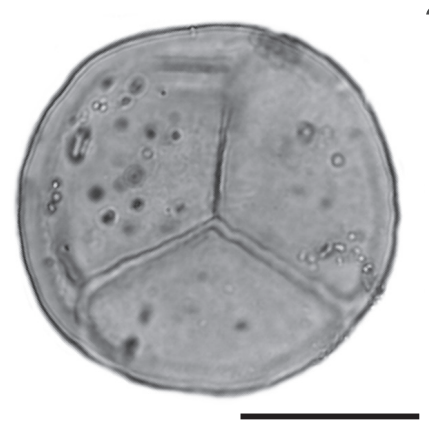

4

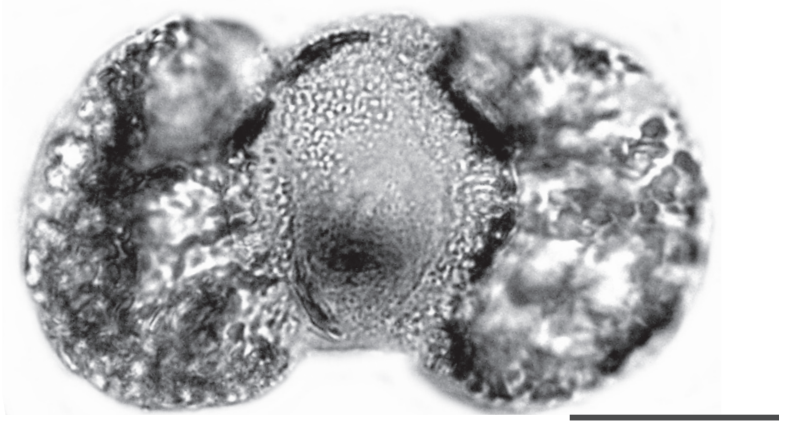

6

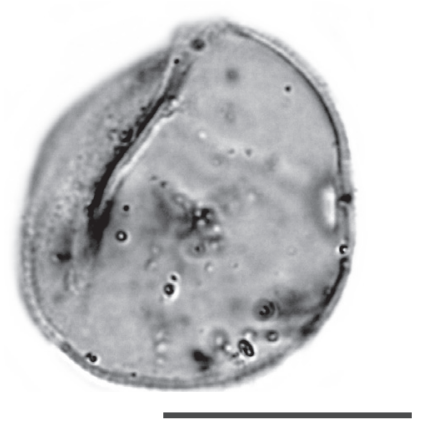

9

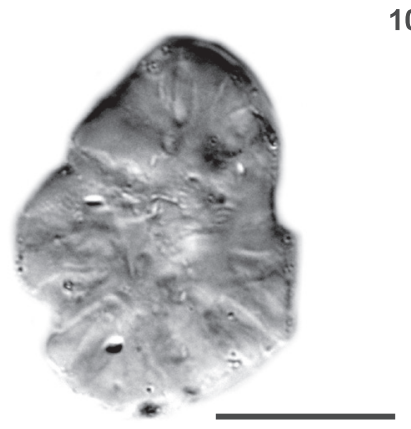

2

10

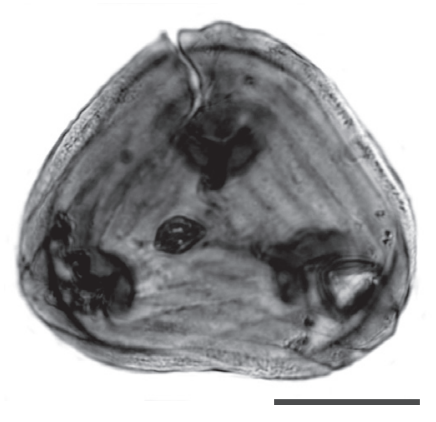

5
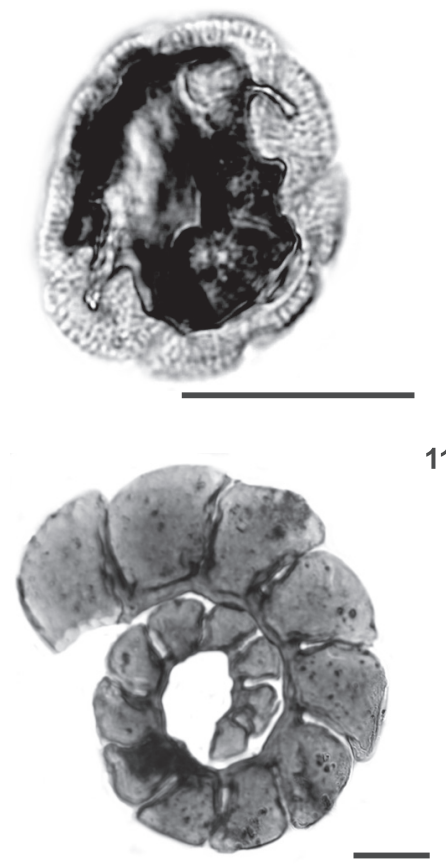
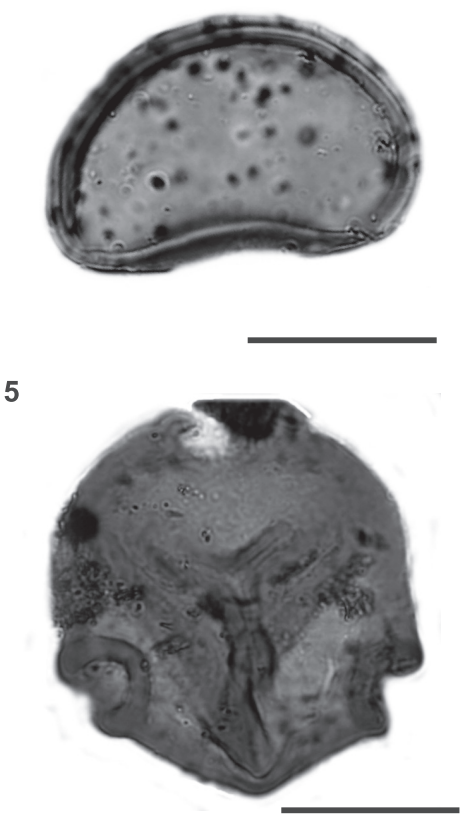

8

3

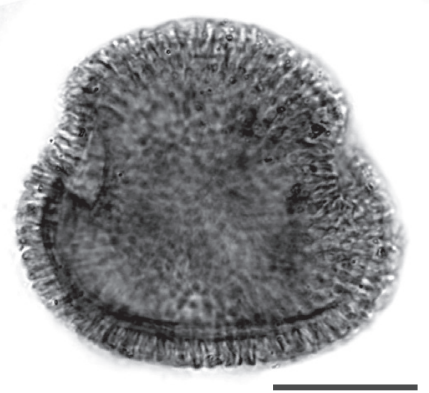

11

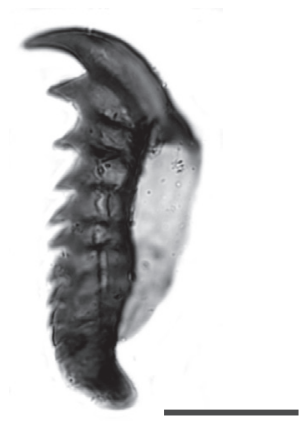

Figura 8. Fotomicrografias de espécimes selecionados. 1. Anthocerotaceae (MP-P 5645, P34-2); 2. Cicatricosisporites sp. 1 (MP-P 5635, M41-4); 3. Laevigatosporites ovatus Wilson e Webster 1946 (MP-P 5621, J33-3); 4. Podocarpidites sp. (MP-P 5639, S39); 5. Corsinipollenites undulatus (Gonzáles Guzmán) Lima e Salard-CheBoldaeff 1981 (MP-P 5619, D43); 6. Poaceae (MP-P 5602, O38-4); 7. Retistephanocolpites gracilis Regali, Uesugui e Santos 1974b (MP-P 5607, T41-4); 8. Rubiaceae (MP-P 5601, M42); 9. Botryococcus sp. (MP-P5601, K37-1); 10. Palinoforaminíferos (MP-P 5642, Q42); 11. Escolecodonte (MP-P 5620, Q33-1). Escala gráfica: $20 \mu \mathrm{m}$. 
